\title{
Urinary 8-OHdG as a Biomarker for Oxidative Stress: A Systematic Literature Review and Meta-Analysis
}

\author{
Melanie Graille ${ }^{1}$, Pascal Wild ${ }^{1,2}$, Jean-Jacques Sauvain ${ }^{1}$, Maud Hemmendinger ${ }^{1}$, \\ Irina Guseva Canu ${ }^{1,+}$ and Nancy B. Hopf $1,3, *,+$ (D) \\ 1 Center for Primary Care and Public Health (Unisanté), University of Lausanne, Route de la Corniche, \\ 21066 Epalinges-Lausanne, Switzerland; MelanieGraille@hotmail.com (M.G.); Pascal.Wild@inrs.fr (P.W.); \\ jean-jacques.sauvain@unisante.ch (J.-J.S.); maud.hemmendinger@unisante.ch (M.H.); \\ irina.guseva-canu@unisante.ch (I.G.C.) \\ 2 Institut national de recherche et de sécurité (INRS), 54000 Nancy, France \\ 3 Swiss Center for Applied Human Toxicology (SCAHT), Missionsstrasse 64, 4055 Basel, Switzerland \\ * Correspondence: nancy.hopf@unisante.ch \\ + Both are last authors.
}

Received: 30 April 2020; Accepted: 22 May 2020; Published: 26 May 2020

\begin{abstract}
Oxidative stress reflects a disturbance in the balance between the production and accumulation of reactive oxygen species (ROS). ROS are scavenged by the antioxidant system, but when in excess concentration, they can oxidize proteins, lipids, and DNA. DNA damage is usually repaired, and the oxidized products are excreted in urine. 8-hydroxy-2-deoxyguanosine is considered a biomarker for oxidative damage of DNA. It is needed to define background ranges for $8-\mathrm{OHdG}$, to use it as a measure of oxidative stress overproduction. We established a standardized protocol for a systematic review and meta-analysis to assess background ranges for urinary 8-OHdG concentrations in healthy populations. We computed geometric mean (GM) and geometric standard deviations (GSD) as the basis for the meta-analysis. We retrieved an initial 1246 articles, included 84 articles, and identified 128 study subgroups. We stratified the subgroups by body mass index, gender, and smoking status reported. The pooled GM value for urinary 8-OHdG concentrations in healthy adults with a mean body mass index (BMI) $\leq 25$ measured using chemical methods was $3.9 \mathrm{ng} / \mathrm{mg}$ creatinine (interquartile range (IQR): 3 to $5.5 \mathrm{ng} / \mathrm{mg}$ creatinine). A significant positive association was observed between smoking and urinary 8-OHdG concentrations when measured by chemical analysis. No gender effect was observed.
\end{abstract}

Keywords: oxidative stress; biomarker; 8-OHdG; systematic review; meta-analysis

\section{Introduction}

Oxidative stress reflects a disturbance in the balance between the production and accumulation of reactive oxygen species (ROS), and an overproduction of ROS has negative consequences for cell physiology [1]. When ROS concentration is in excess, oxidative damage to proteins, lipids, and DNA occurs, thus causing structural and functional cellular changes. DNA damage is usually repaired primarily via the base excision repair pathway, and oxidized products are excreted in urine [2]. 8-hydroxy-2-deoxyguanosine (8-OHdG) is one of the most widely studied oxidized metabolites and is considered as a biomarker for oxidative damage of DNA [3,4]. The formation of 8-OHdG by oxygen radicals was first reported in 1984 by Kasai and Nishimura [5].

The interaction of the hydroxyl radical, the most important oxygen-free radical, with the nucleobases of the DNA strand, such as guanine, leads to the formation of 8-OHdG [6] (Figure 1). 


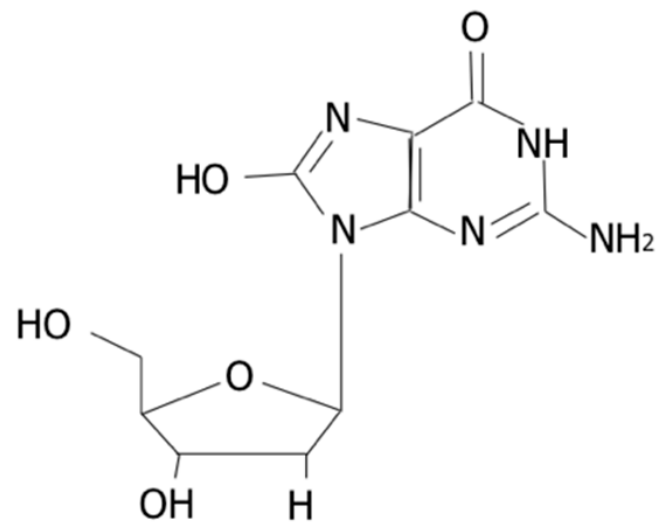

Figure 1. Structure of $8-\mathrm{OHdG}$.

Some diseases, such as cardiovascular or chronic obstructive pulmonary diseases (COPD), have been associated with excessive concentrations of 8-OHdG [7,8]. 8-OHdG levels also increase due to smoking, aging, or occupational exposure to physical, chemical, or biological substances $[9,10]$.

A recent study suggested that $8-\mathrm{OHdG}$ had high intraclass correlation coefficients (0.96), reproducible measurements, and low coefficients of variation and was the most suitable biomarker of oxidative stress in spot urine samples [11]. Concentrations of urinary oxidative stress biomarkers have been proposed as an effect biomarker to survey populations exposed to xenobiotics such as particulates, oxidizing agents, and lately, engineered nanomaterials [12,13].

Measuring urinary 8-OHdG has some advantages as it is very stable in urine [14], it is noninvasive, and its excretion is likely to reflect the oxidative DNA damage [15] and can be assessed by two main analytical techniques: mass-based methods (using either gas (GC) or liquid (LC) chromatography) and immunological methods. Another source of 8-OHdG in urine is DNA polymerase-dependent incorporation of 8-oxodGTP from the nucleotide pool [16]. Chromatographic methods are considered to be the gold standard; however, immunological techniques, which are less costly and time-consuming, are widely used because enzyme-linked immunosorbent assay (ELISA) kits have been developed for rapid detection and quantification of 8-OHdG [14,17].

A background range for $8-\mathrm{OHdG}$ has been reported in different studies for healthy persons $[11,18-20]$. However, these studies reported a wider range of values, making the identification of background cut-off values challenging.

Therefore, the systematic review and meta-analyses of the reported values appears the most appropriate approach to bypass this issue. Our objective was to assess background ranges for urinary 8-OHdG concentrations in healthy adults.

\section{Results}

Chemical methods were used in 44 of the 128 study subgroups, and immunological techniques were used in 84 (Table 1). We decided to stratify the subgroups by body mass index (BMI), gender, and smoking status reported. 
Table 1. Summary of geometric mean urinary 8-OHdG concentrations (ng/mg creatinine) in subgroups of healthy adult (18+ years) participants.

\begin{tabular}{|c|c|c|c|c|c|c|}
\hline & $\mathrm{BMI} \leq 25$ & & & $\mathrm{BMI}>25$ & & \\
\hline $\begin{array}{l}\text { Analytical } \\
\text { Techniques }\end{array}$ & $\begin{array}{l}\text { All } \\
\text { Participants }\end{array}$ & $\begin{array}{l}\text { Smoking } \\
\text { Status }\end{array}$ & & $\begin{array}{l}\text { All } \\
\text { Participants }\end{array}$ & $\begin{array}{l}\text { Smoking } \\
\text { Status }\end{array}$ & \\
\hline \multirow{2}{*}{ Chemical } & \multirow{2}{*}{$\begin{array}{l}3.9^{*} \\
(3-5.5) \\
\left(n^{* *}=31\right)\end{array}$} & $\begin{array}{l}\text { Nonsmokers } \\
(n=14)\end{array}$ & $\begin{array}{l}4.3 \\
(2.9-5.5) \\
\end{array}$ & \multirow{2}{*}{$\begin{array}{l}2.8 \\
(2.4-3.5) \\
(n=9)\end{array}$} & $\begin{array}{l}\text { Nonsmokers } \\
(n=3)\end{array}$ & $\begin{array}{l}2.5 \\
(1.9-2.8)\end{array}$ \\
\hline & & $\begin{array}{l}\text { Smokers } \\
(n=2)\end{array}$ & $\begin{array}{l}22.2 \\
(3-41.4)\end{array}$ & & $\begin{array}{l}\text { Smokers } \\
(n=2)\end{array}$ & $\begin{array}{l}4.0 \\
(3.5-4.5)\end{array}$ \\
\hline \multirow{2}{*}{ Immunological } & \multirow{2}{*}{$\begin{array}{l}9.0 \\
(5.9-19.8) \\
(n=47)\end{array}$} & $\begin{array}{l}\text { Nonsmokers } \\
(n=24)\end{array}$ & $\begin{array}{l}11.5 \\
(5.9-21.6)\end{array}$ & \multirow{2}{*}{$\begin{array}{l}7.7 \\
(5.8-10.9) \\
(n=26)\end{array}$} & $\begin{array}{l}\text { Nonsmokers } \\
(n=13)\end{array}$ & $\begin{array}{l}9.3 \\
(7.8-14.7)\end{array}$ \\
\hline & & $\begin{array}{l}\text { Smokers } \\
(n=0)\end{array}$ & NA & & $\begin{array}{l}\text { Smokers } \\
(n=6)\end{array}$ & $\begin{array}{l}6.0 \\
(5.4-7)\end{array}$ \\
\hline
\end{tabular}

${ }^{*}$ Median (IQR: $\left.25 \%-75 \%\right) ;{ }^{* *}$ Number of included study subgroups; NA: Not Available.

\subsection{Descriptive Results}

We retrieved 1246 articles, included 84 articles, and considered 129 study subgroups (Figure 2, Tables 2-5) in the quantitative synthesis, which we stratified by main quantification techniques: immunological and chemical methods. For subgroups evaluated with the chemical methods, 31 studies had participants with a mean BMI between 18 and 25 (14 study subgroups of nonsmokers and 2 study subgroups of smokers) (Figure 3, Table 2). Nine studies had participants with a mean BMI > 25 (three study subgroups of nonsmokers and two study subgroups of smokers) (Figure 4, Table 3). The mean BMI was unknown for four study subgroups.
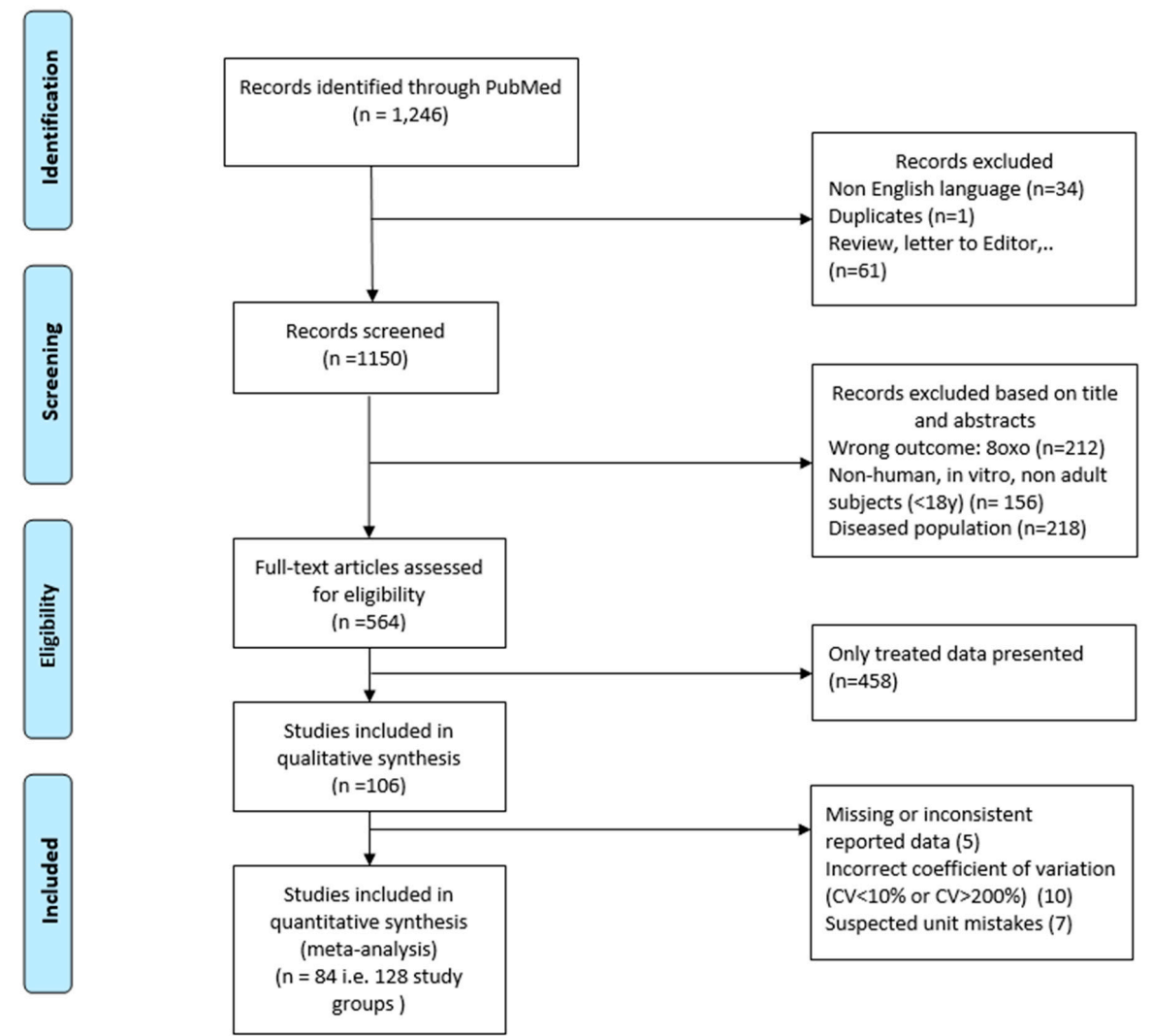

Figure 2. Flow chart of study selection. 
Table 2. References for urinary 8-OHdG concentrations and computed GM (ng/mg creatinine) measured with chemical techniques in healthy (mean BMI $\leq 25$ and no known disease), adult (18+ years) participants.

\begin{tabular}{|c|c|c|c|c|c|c|c|c|c|c|c|c|c|c|c|c|c|c|c|}
\hline Reference & $\begin{array}{l}\text { Study } \\
\text { Group }\end{array}$ & $\begin{array}{l}\text { Analytic } \\
\text { Method }\end{array}$ & Sample & Country & $\begin{array}{c}\text { Sample } \\
\text { Size }\end{array}$ & $\begin{array}{l}\text { Mean } \\
\text { Age }\end{array}$ & Female & Male & $\begin{array}{l}\text { Smoking } \\
\text { Status }\end{array}$ & $\begin{array}{c}\text { Mean } \\
\text { BMI }\end{array}$ & AM & GM & IQR & Range & Median & CI & $\begin{array}{c}\text { Units } \\
\text { (8-OHdG/ } \\
\text { Creatinine) }\end{array}$ & $\begin{array}{l}\text { Computed } \\
\text { GM (ng/mg } \\
\text { Creatinine) }\end{array}$ & GSD \\
\hline [21] & $\begin{array}{l}\text { Control } \\
\text { group }\end{array}$ & HPLC & $\begin{array}{l}\text { spot } \\
\text { urine }\end{array}$ & China & 497 & 42.48 & 113 & 384 & $50 \%$ & 23.72 & $\begin{array}{l}4.47 \pm \\
1.26^{*}\end{array}$ & & & & & & $\mathrm{nmol} / \mathrm{mmol}$ & 11 & 1 \\
\hline [22] & $\begin{array}{l}\text { Control } \\
\text { group }\end{array}$ & $\begin{array}{l}\text { HPLC- } \\
\text { MS/MS }\end{array}$ & $\begin{array}{l}\text { spot } \\
\text { urine }\end{array}$ & China & 106 & 31.62 & 0 & 106 & $52.8 \%$ & 23.79 & $\begin{array}{c}3 \pm 1.08 \\
*\end{array}$ & & & & & & $\mu \mathrm{g} / \mathrm{g}$ & 3 & 1 \\
\hline [23] & $\begin{array}{l}\text { Selenium } \\
\text { group } \\
\text { baseline } \\
\text { value }\end{array}$ & $\begin{array}{c}\text { HPLC } \\
\text { with EC } \\
\text { detection }\end{array}$ & $\begin{array}{c}\text { spot } \\
\text { urine }\end{array}$ & USA & 17 & 30.7 & 0 & 17 & $0 \%$ & 24.2 & $\begin{array}{l}3.16 \pm \\
1.28^{*}\end{array}$ & & & & & & $\mathrm{ng} / \mathrm{mg}$ & 3 & 1 \\
\hline [24] & $\begin{array}{l}\text { Baseline } \\
\text { value }\end{array}$ & $\begin{array}{l}\text { UPLC-MS } \\
\text {-MS in } \\
\text { positive EI } \\
\text { mode }\end{array}$ & $\begin{array}{l}\text { spot } \\
\text { urine }\end{array}$ & Belgium & 48 & 40 & 3 & 45 & $31.2 \%$ & 24.2 & $\begin{array}{c}10.76 \pm \\
2.83 *\end{array}$ & & & $7.05-20.92$ & & & $\mu \mathrm{g} / \mathrm{g}$ & 10 & 1 \\
\hline [25] & $\begin{array}{c}\text { Men } \\
\text { baseline }\end{array}$ & HPLC & $\begin{array}{c}\text { spot } \\
\text { urine }\end{array}$ & Japan & 2370 & 60.7 & 0 & 2370 & $24.9 \%$ & 23.6 & & $\begin{array}{c}3.7 \pm 1.6 \\
*\end{array}$ & & & & & $\mathrm{ng} / \mathrm{mg}$ & 4 & 2 \\
\hline [25] & $\begin{array}{l}\text { Women } \\
\text { baseline }\end{array}$ & HPLC & $\begin{array}{l}\text { spot } \\
\text { urine }\end{array}$ & Japan & 4052 & 60.2 & 4052 & 0 & $4.7 \%$ & 22.2 & & $\begin{array}{c}4.1 \pm 1.7 \\
*\end{array}$ & & & & & $\mathrm{ng} / \mathrm{mg}$ & 4 & 2 \\
\hline [26] & $\begin{array}{l}\text { Baseline } \\
\text { value }\end{array}$ & LC-MS/MS & $\begin{array}{c}\text { spot } \\
\text { urine }\end{array}$ & Taiwan & 58 & 23.84 & 0 & 58 & $51.7 \%$ & 24.55 & & & $2.63-11.54$ & & 4.42 & & $\mu \mathrm{g} / \mathrm{g}$ & 16 & 2 \\
\hline [27] & $\begin{array}{c}\text { Service } \\
\text { staff group }\end{array}$ & HPLC & $\begin{array}{l}\text { spot } \\
\text { urine }\end{array}$ & China & 67 & 24.8 & 0 & 67 & $0 \%$ & 23.2 & & & & & 1.4 & $0.9-1.8$ & $\mu \mathrm{mol} / \mathrm{mol}$ & 2 & 3 \\
\hline [28] & $\begin{array}{c}\text { All } \\
\text { population }\end{array}$ & HPLC & $\begin{array}{l}\text { spot } \\
\text { urine }\end{array}$ & Japan & 503 & 42.4 & 209 & 294 & $27.4 \%$ & 22.5 & & & $2.37-4.03$ & $0.8-10.0$ & 3.01 & & $\mu \mathrm{g} / \mathrm{g}$ & 3 & 1 \\
\hline [29] & $\begin{array}{l}\text { Baseline } \\
\text { value }\end{array}$ & HPLC & $\begin{array}{l}\text { spot } \\
\text { urine }\end{array}$ & Korea & 102 & 55 & 102 & 0 & $0 \%$ & 24.1 & $\begin{array}{c}6.5 \pm 3.9 \\
*\end{array}$ & & & & & & $\mu \mathrm{g} / \mathrm{g}$ & 6 & 2 \\
\hline [30] & $\begin{array}{l}\text { Control } \\
\text { group }\end{array}$ & HPLC & $\begin{array}{c}\text { spot } \\
\text { urine }\end{array}$ & Japan & 805 & 40.3 & 0 & 805 & $46.7 \%$ & 23.7 & $\begin{array}{l}3.79 \pm \\
1.44^{*}\end{array}$ & & & & & & $\mathrm{ng} / \mathrm{mg}$ & 4 & 1 \\
\hline [31] & $\begin{array}{l}\text { Baseline } \\
\text { value }\end{array}$ & GC-MS & $\begin{array}{c}\text { spot } \\
\text { urine }\end{array}$ & Singapore & 24 & 22.8 & NA & NA & $0 \%$ & 21.6 & $\begin{array}{l}2.02 \pm \\
1.12 *\end{array}$ & & & & & & $\mu \mathrm{mol} / \mathrm{mol}$ & 5 & 2 \\
\hline [32] & $\begin{array}{c}\text { Non } \\
\text { smoker } \\
\text { group } \\
\text { baseline }\end{array}$ & $\begin{array}{c}\text { HPLC } \\
\text { with EC } \\
\text { detection }\end{array}$ & $\begin{array}{c}24 \mathrm{~h} \\
\text { urine }\end{array}$ & China & 30 & 21.5 & 0 & 30 & $0 \%$ & 22.8 & $\underset{* *}{6.3 \pm 0.5}$ & & & & & & $\mu \mathrm{mol} / \mathrm{mol}$ & 14 & 2 \\
\hline
\end{tabular}


Table 2. Cont.

\begin{tabular}{|c|c|c|c|c|c|c|c|c|c|c|c|c|c|c|c|c|c|c|c|}
\hline Reference & $\begin{array}{l}\text { Study } \\
\text { Group }\end{array}$ & $\begin{array}{l}\text { Analytic } \\
\text { Method }\end{array}$ & Sample & Country & $\begin{array}{l}\text { Sample } \\
\text { Size }\end{array}$ & $\begin{array}{l}\text { Mean } \\
\text { Age }\end{array}$ & Female & Male & $\begin{array}{c}\text { Smoking } \\
\text { Status }\end{array}$ & $\begin{array}{c}\text { Mean } \\
\text { BMI }\end{array}$ & AM & GM & IQR & Range & Median & CI & $\begin{array}{c}\text { Units } \\
\text { (8-OHdG/ } \\
\text { Creatinine) }\end{array}$ & $\begin{array}{l}\text { Computed } \\
\text { GM (ng/mg } \\
\text { Creatinine) }\end{array}$ & GSD \\
\hline [32] & $\begin{array}{c}\text { Smoker } \\
\text { group } \\
\text { baseline }\end{array}$ & $\begin{array}{c}\text { HPLC } \\
\text { with EC } \\
\text { detection }\end{array}$ & $\begin{array}{c}24 \mathrm{~h} \\
\text { urine }\end{array}$ & China & 60 & 21.8 & 0 & 60 & $100 \%$ & 22.6 & $18 \pm 1^{* *}$ & & & & & & $\mu \mathrm{mol} / \mathrm{mol}$ & 41 & 2 \\
\hline [33] & $\begin{array}{l}\text { Participants } \\
\text { without } \\
\text { stroke }\end{array}$ & LC-MS/MS & $\begin{array}{l}\text { spot } \\
\text { urine }\end{array}$ & Taiwan & 131 & 64.9 & 57 & 74 & $50 \%$ & 22.9 & & & $8.3-22.8$ & & 13 & & $\mu \mathrm{g} / \mathrm{g}$ & 13 & 2 \\
\hline [34] & $\begin{array}{c}\text { Male } \\
\text { baseline }\end{array}$ & HPLC-EC & $\begin{array}{c}\text { spot } \\
\text { urine }\end{array}$ & Japan & 79 & 47.9 & 0 & 79 & $0 \%$ & 22.3 & $\begin{array}{l}2.81 \pm \\
1.07^{*} \\
\end{array}$ & & & & & & $\mu \mathrm{g} / \mathrm{g}$ & 3 & 2 \\
\hline [34] & $\begin{array}{c}\text { Female } \\
\text { baseline }\end{array}$ & HPLC-EC & $\begin{array}{l}\text { spot } \\
\text { urine }\end{array}$ & Japan & 16 & 46.7 & 16 & 0 & $0 \%$ & 20.6 & $\begin{array}{l}3.04 \pm \\
1.42 *\end{array}$ & & & & & & $\mu \mathrm{g} / \mathrm{g}$ & 3 & 1 \\
\hline [35] & $\begin{array}{l}\text { Women } \\
\text { baseline }\end{array}$ & HPLC & $\begin{array}{c}\text { spot } \\
\text { urine }\end{array}$ & Japan & 37 & $28-57$ & 37 & 0 & $5.4 \%$ & 21.5 & & & $3.2-5.2$ & & 3.9 & & $\mu \mathrm{g} / \mathrm{g}$ & 4 & 1 \\
\hline [35] & $\begin{array}{c}\text { Non } \\
\text { smoking } \\
\text { men group } \\
\text { baseline }\end{array}$ & HPLC & $\begin{array}{l}\text { spot } \\
\text { urine }\end{array}$ & Japan & 87 & $28-57$ & 0 & 87 & $0 \%$ & 24.2 & & & $2.9-4.7$ & & 3.6 & & $\mu \mathrm{g} / \mathrm{g}$ & 4 & 1 \\
\hline [36] & $\begin{array}{l}\text { Baseline } \\
\text { value }\end{array}$ & $\begin{array}{c}\text { HPLC } \\
\text { with an EC } \\
\text { detector }\end{array}$ & $\begin{array}{l}\text { spot } \\
\text { urine }\end{array}$ & Japan & 23 & 46.8 & 11 & 12 & $100 \%$ & 23.6 & & 3.02 & & & & $2.24-4.07$ & $07 \mathrm{ng} / \mathrm{mg}$ & 5 & 1 \\
\hline [37] & $\begin{array}{l}\text { Control } \\
\text { group }\end{array}$ & LC-MS/MS & $\begin{array}{c}\text { spot } \\
\text { urine }\end{array}$ & Taiwan & 125 & 34.1 & 0 & 125 & $0 \%$ & 22.8 & & $\begin{array}{c}4.1 \pm 2.1 \\
*\end{array}$ & & & & & $\mu \mathrm{g} / \mathrm{g}$ & 4 & 2 \\
\hline [38] & $\begin{array}{l}\text { Control } \\
\text { group }\end{array}$ & HPLC-MS/MS & $\begin{array}{c}\text { spot } \\
\text { urine }\end{array}$ & China & 185 & 40.4 & 124 & 61 & $0 \%$ & 24.4 & & $\begin{array}{c}5.5 \pm 2.2 \\
*\end{array}$ & & & & & $\mu \mathrm{g} / \mathrm{g}$ & 6 & 2 \\
\hline [39] & $\begin{array}{l}\text { Control } \\
\text { group }\end{array}$ & LC EC & $\begin{array}{c}\text { spot } \\
\text { urine }\end{array}$ & India & 135 & 41.31 & 0 & 135 & $0 \%$ & 22.38 & $\begin{array}{l}3.57 \pm \\
0.63^{*}\end{array}$ & & & & & & $\mu \mathrm{mol} / \mathrm{mol}$ & 9 & 1 \\
\hline [40] & $\begin{array}{c}\text { All } \\
\text { population }\end{array}$ & HPLC & $\begin{array}{c}\text { spot } \\
\text { urine }\end{array}$ & Japan & 6517 & 60.3 & 4064 & 2453 & $12.6 \%$ & 22.7 & & $\begin{array}{c}3.9 \pm 1.6 \\
*\end{array}$ & & & & & $\mathrm{ng} / \mathrm{mg}$ & 4 & 2 \\
\hline [41] & $\begin{array}{l}\text { Placebo } \\
\text { group end } \\
\text { of study }\end{array}$ & LC-MS/MS & $\begin{array}{l}\text { spot } \\
\text { urine }\end{array}$ & USA & 12 & 69 & 6 & 6 & $0 \%$ & 25 & $\underset{* *}{2 \pm 0.2}$ & & & & & & $\mu \mathrm{mol} / \mathrm{mol}$ & 5 & 1 \\
\hline [41] & $\begin{array}{c}\text { Tart } \\
\text { cherryjuice } \\
\text { group end } \\
\text { of study }\end{array}$ & LC-MS/MS & $\begin{array}{c}\text { spot } \\
\text { urine }\end{array}$ & USA & 12 & 69 & 6 & 6 & $0 \%$ & 25 & $1.8 \pm 0.1$ & & & & & & $\mu \mathrm{mol} / \mathrm{mol}$ & 4 & 1 \\
\hline [42] & $\begin{array}{l}\text { Male } \\
\text { group }\end{array}$ & LC-MS/MS & $\begin{array}{c}\text { spot } \\
\text { urine }\end{array}$ & China & 69 & 37.83 & 0 & 69 & $43.5 \%$ & 24.1 & $\begin{array}{l}4.55 \pm \\
4.44^{*}\end{array}$ & & & & & & $\mu \mathrm{g} / \mathrm{g}$ & 3 & 2 \\
\hline
\end{tabular}


Table 2. Cont.

\begin{tabular}{|c|c|c|c|c|c|c|c|c|c|c|c|c|c|c|c|c|c|c|}
\hline Reference & $\begin{array}{l}\text { Study } \\
\text { Group }\end{array}$ & $\begin{array}{l}\text { Analytic } \\
\text { Method }\end{array}$ & Sample & Country & $\begin{array}{l}\text { Sample } \\
\text { Size }\end{array}$ & $\begin{array}{c}\text { Mean } \\
\text { Age }\end{array}$ & Female & Male & $\begin{array}{l}\text { Smoking } \\
\text { Status }\end{array}$ & $\begin{array}{c}\text { Mean } \\
\text { BMI }\end{array}$ & AM & GM & IQR & Range & Median CI & $\begin{array}{c}\text { Units } \\
\text { (8-OHdG/ } \\
\text { Creatinine) }\end{array}$ & $\begin{array}{c}\text { Computed } \\
\text { GM (ng/mg } \\
\text { Creatinine) }\end{array}$ & GSD \\
\hline [42] & $\begin{array}{c}\text { Female } \\
\text { group }\end{array}$ & LC-MS/MS & $\begin{array}{l}\text { spot } \\
\text { urine }\end{array}$ & China & 23 & 38.55 & 23 & 0 & $0 \%$ & 22.1 & $\begin{array}{l}4.34 \pm \\
3.85 \text { * }\end{array}$ & & & & & $\mu \mathrm{g} / \mathrm{g}$ & 3 & 2 \\
\hline [43] & $\begin{array}{l}\text { Control } \\
\text { group }\end{array}$ & LC-MS/MS & $\begin{array}{l}\text { spot } \\
\text { urine }\end{array}$ & Taiwan & 129 & 51.7 & 39 & 90 & $27.9 \%$ & 24.6 & $\begin{array}{c}4.3 \pm 0.5 \\
* *\end{array}$ & & & & & $\mathrm{ng} / \mathrm{mg}$ & 3 & 3 \\
\hline [44] & $\begin{array}{l}\text { Men } \\
\text { group }\end{array}$ & HPLC & $\begin{array}{l}\text { spot } \\
\text { urine }\end{array}$ & Japan & 196 & 44.4 & 0 & 196 & $43.9 \%$ & 23.8 & $\begin{array}{c}3.3 \pm 1.1 \\
*\end{array}$ & & & & & $\mu \mathrm{g} / \mathrm{g}$ & 3 & 1 \\
\hline [44] & $\begin{array}{l}\text { Women } \\
\text { group }\end{array}$ & HPLC & $\begin{array}{l}\text { spot } \\
\text { urine }\end{array}$ & Japan & 136 & 40.4 & 136 & 0 & $2.9 \%$ & 21 & $\begin{array}{c}3.3 \pm 1.1 \\
*\end{array}$ & & & & & $\mu \mathrm{g} / \mathrm{g}$ & 3 & 1 \\
\hline
\end{tabular}

Table 3. References for urinary 8-OHdG concentrations measured and computed GM (ng/mg creatinine) with chemical techniques in healthy (mean BMI > 25 and no known disease), adult (18+ years) participants.

\begin{tabular}{|c|c|c|c|c|c|c|c|c|c|c|c|c|c|c|c|c|}
\hline Reference & Study Group & $\begin{array}{l}\text { Analytic } \\
\text { Method }\end{array}$ & Sample & Country & $\begin{array}{l}\text { Sample } \\
\text { Size }\end{array}$ & $\begin{array}{c}\text { Mean } \\
\text { Age }\end{array}$ & Female & Male & $\begin{array}{l}\text { Smoking } \\
\text { Status }\end{array}$ & $\begin{array}{c}\text { Mean } \\
\text { BMI }\end{array}$ & $\mathrm{AM}$ & IQR & Median & $\begin{array}{c}\text { Units } \\
\text { (8-OHdG/ } \\
\text { Creatinine) }\end{array}$ & $\begin{array}{c}\text { Computed GM } \\
\text { (ng/mg } \\
\text { Creatinine) }\end{array}$ & GSD \\
\hline [45] & $\begin{array}{l}\text { Elderly low } \\
\text { expose group }\end{array}$ & LC-MS/MS & $\begin{array}{l}\text { spot } \\
\text { urine }\end{array}$ & Taiwan & 71 & 66.36 & 36 & 35 & $9.9 \%$ & 26.36 & $3.16 \pm 4.07 *$ & & & $\mu \mathrm{g} / \mathrm{g}$ & 3 & 2 \\
\hline [23] & Placebo group & $\begin{array}{l}\text { HPLC with } \\
\text { EC detection }\end{array}$ & $\begin{array}{c}\text { spot } \\
\text { urine }\end{array}$ & USA & 19 & 31.1 & 0 & 19 & $0 \%$ & 25.2 & $4.18 \pm 4.78^{*}$ & & & $\mathrm{ng} / \mathrm{mg}$ & 3 & 2 \\
\hline [46] & Control group & LC/MS/MS & $\begin{array}{l}\text { spot } \\
\text { urine }\end{array}$ & Taiwan & 168 & 43.2 & NA & NA & $34 \%$ & 26.4 & $10.61 \pm 7.77^{*}$ & & & $\mu \mathrm{mol} / \mathrm{mol}$ & 21 & 2 \\
\hline [47] & Control group & HPLC & $\begin{array}{l}\text { spot } \\
\text { urine }\end{array}$ & China & 31 & 38.7 & 0 & 31 & $19.4 \%$ & $\begin{array}{l}\leq 2438.7 \% \\
>2461.3 \%\end{array}$ & & $1.0-4.0$ & 1.3 & $\mu \mathrm{mol} / \mathrm{mol}$ & 3 & 3 \\
\hline [48] & $\begin{array}{l}\text { Control non } \\
\text { smoker group }\end{array}$ & HPLC-ECD & $\begin{array}{l}\text { spot } \\
\text { urine }\end{array}$ & Turkey & 19 & 54.8 & 3 & 16 & $0 \%$ & 29.1 & $2.1 \pm 1^{*}$ & & & $\mu \mathrm{g} / \mathrm{g}$ & 2 & 1 \\
\hline [48] & $\begin{array}{c}\text { Control } \\
\text { ex-smoker group }\end{array}$ & HPLC-ECD & $\begin{array}{l}\text { spot } \\
\text { urine }\end{array}$ & Turkey & 21 & 57.5 & 3 & 18 & $0 \%$ & 27.2 & $2.6 \pm 0.8^{*}$ & & & $\mu \mathrm{g} / \mathrm{g}$ & 2 & 2 \\
\hline [48] & $\begin{array}{l}\text { Control smoker } \\
\text { group }\end{array}$ & HPLC-ECD & $\begin{array}{l}\text { spot } \\
\text { urine }\end{array}$ & Turkey & 24 & 51.1 & 4 & 20 & $100 \%$ & 26.5 & $4.2 \pm 2.8^{*}$ & & & $\mu \mathrm{g} / \mathrm{g}$ & 3 & 2 \\
\hline [35] & $\begin{array}{l}\text { Smoking men } \\
\text { group baseline }\end{array}$ & HPLC & $\begin{array}{l}\text { spot } \\
\text { urine }\end{array}$ & Japan & 40 & $28-57$ & 0 & 40 & $100 \%$ & 25.1 & & $3.6-5.6$ & 4.5 & $\mu \mathrm{g} / \mathrm{g}$ & 4 & 1 \\
\hline [49] & $\begin{array}{l}\text { Control group } \\
\text { baseline }\end{array}$ & HPLC & $\begin{array}{l}\text { spot } \\
\text { urine }\end{array}$ & USA & 20 & 39 & 20 & 0 & $50 \%$ & 29 & $2.8 \pm 1.7^{*}$ & & & $\mu \mathrm{g} / \mathrm{g}$ & 2 & 2 \\
\hline
\end{tabular}


Table 4. References for urinary 8-OHdG concentrations measured and computed GM (ng/mg creatinine) with immunological techniques in healthy (mean BMI $\leq 25$ and no known disease), adult (18+ years) participants.

\begin{tabular}{|c|c|c|c|c|c|c|c|c|c|c|c|c|c|c|c|c|c|c|}
\hline Reference & $\begin{array}{l}\text { Study } \\
\text { Group }\end{array}$ & Sample & Country & $\begin{array}{l}\text { Sample } \\
\text { Size }\end{array}$ & $\begin{array}{c}\text { Mean } \\
\text { Age }\end{array}$ & Female & Male & $\begin{array}{l}\text { Smoking } \\
\text { Status }\end{array}$ & $\begin{array}{c}\text { Mean } \\
\text { BMI }\end{array}$ & AM & GM & IQR & Range & Median & CI & $\begin{array}{c}\text { Units } \\
\text { (8-OHdG/ } \\
\text { Creatinine) }\end{array}$ & $\begin{array}{c}\text { Computed } \\
\text { GM } \\
(\mathrm{ng} / \mathrm{mg} \\
\text { Creatinine) }\end{array}$ & GSD \\
\hline [50] & $\begin{array}{c}\text { Healthy } \\
\text { control group }\end{array}$ & $\begin{array}{l}24 \mathrm{~h} \\
\text { urine }\end{array}$ & Thailand & 30 & 41.43 & 19 & 11 & NA & 22.56 & $4.32 \pm 4.93 *$ & & & & & & $\mu \mathrm{g} / \mathrm{g}$ & 3 & 2 \\
\hline [51] & $\begin{array}{c}\text { Healthy } \\
\text { control group }\end{array}$ & $\begin{array}{l}24 \mathrm{~h} \\
\text { urine }\end{array}$ & Thailand & 30 & 41.43 & 19 & 11 & NA & 22.56 & $5.27 \pm 2.77^{*}$ & & & & & & $\mu \mathrm{g} / \mathrm{g}$ & 5 & 2 \\
\hline [52] & $\begin{array}{l}\text { Control } \\
\text { group }\end{array}$ & $\begin{array}{l}\text { spot } \\
\text { urine }\end{array}$ & China & 35 & 60 & 15 & 20 & $0 \%$ & 22.9 & $11.9 \pm 4.9^{*}$ & & & & & & $\mathrm{ng} / \mathrm{mg}$ & 11 & 1 \\
\hline [53] & $\begin{array}{l}\text { Control } \\
\text { group }\end{array}$ & $\begin{array}{l}\text { spot } \\
\text { urine }\end{array}$ & Korea & 416 & 64.4 & 92 & 324 & $28.1 \%$ & 23.7 & & 5.06 & & & & $4.55-5.62$ & $2 \mu \mathrm{g} / \mathrm{g}$ & 5 & 2 \\
\hline [54] & $\begin{array}{l}\text { Control } \\
\text { group }\end{array}$ & $\begin{array}{l}\text { spot } \\
\text { urine }\end{array}$ & Korea & 140 & 68.8 & 32 & 108 & $65.5 \%$ & 22.46 & & 4.88 & & & & $4.43-5.38$ & $\mu \quad \mu g / g$ & 5 & 1 \\
\hline [55] & $\begin{array}{c}\text { Healthy } \\
\text { young group }\end{array}$ & $\begin{array}{l}24 \mathrm{~h} \\
\text { urine }\end{array}$ & Canada & 12 & 22.8 & 0 & 12 & $0 \%$ & 25 & $\begin{array}{c}5333 \pm \\
*\end{array}$ & & & & & & $\mathrm{ng} / \mathrm{g}$ & 5 & 1 \\
\hline [56] & $\begin{array}{l}\text { Apple group } \\
\text { final value }\end{array}$ & $\begin{array}{l}\text { spot } \\
\text { urine }\end{array}$ & China & 13 & 62.8 & 3 & 10 & $0 \%$ & 24.2 & $\begin{array}{l}824.41 \pm \\
343.66^{*}\end{array}$ & & & & & & $\mathrm{ng} / \mathrm{mmol}$ & 7 & 1 \\
\hline [56] & $\begin{array}{l}\text { Pomegranate } \\
\text { group final } \\
\text { value }\end{array}$ & $\begin{array}{l}\text { spot } \\
\text { urine }\end{array}$ & China & 13 & 64.1 & 3 & 10 & $0 \%$ & 23 & $\begin{array}{l}651.57 \pm \\
332.44^{*}\end{array}$ & & & & & & $\mathrm{ng} / \mathrm{mmol}$ & 5 & 2 \\
\hline [57] & $\begin{array}{l}\text { placebo } \\
\text { group } \\
\text { baseline } \\
\text { value }\end{array}$ & $\begin{array}{l}\text { spot } \\
\text { urine }\end{array}$ & China & 150 & 51.58 & 92 & 58 & $41.3 \%$ & 23.8 & & $60.89 \pm 1.62^{*}$ & & & 58.19 & & $\mathrm{ng} / \mathrm{mg}$ & 61 & 2 \\
\hline [57] & $\begin{array}{l}\text { Baseline line } \\
\text { value Low } \\
\text { FA group }\end{array}$ & $\begin{array}{l}\text { spot } \\
\text { urine }\end{array}$ & China & 145 & 48.9 & 87 & 58 & $33.8 \%$ & 24.5 & & $\begin{array}{c}55.48 \pm 1.74 \\
*\end{array}$ & & & 53.51 & & $\mathrm{ng} / \mathrm{mg}$ & 55 & 2 \\
\hline [57] & $\begin{array}{l}\text { Baseline } \\
\text { value high } \\
\text { FA group }\end{array}$ & $\begin{array}{l}\text { spot } \\
\text { urine }\end{array}$ & China & 143 & 48.66 & 94 & 49 & $30.1 \%$ & 24.6 & & $\underset{*}{55.81 \pm 1.72}$ & & & 54.73 & & $\mathrm{ng} / \mathrm{mg}$ & 56 & 2 \\
\hline [58] & $\begin{array}{l}\text { Control } \\
\text { group }\end{array}$ & $\begin{array}{l}24 \mathrm{~h} \\
\text { urine }\end{array}$ & Japan & 15 & 40 & 6 & 9 & $0 \%$ & 23.2 & $9.7 \pm 4.6$ * & & & & & & $\mathrm{ng} / \mathrm{mg}$ & 9 & 2 \\
\hline [59] & $\begin{array}{l}\text { Control } \\
\text { group I }\end{array}$ & $\begin{array}{l}\text { spot } \\
\text { urine }\end{array}$ & China & 20 & 25.55 & 17 & 3 & $0 \%$ & 19.74 & $\underset{* *}{10.68 \pm 1.07}$ & & & & & & $\mathrm{ng} / \mathrm{mg}$ & 10 & 2 \\
\hline [59] & $\begin{array}{l}\text { Control } \\
\text { group II }\end{array}$ & $\begin{array}{l}\text { spot } \\
\text { urine }\end{array}$ & China & 20 & 24.5 & 15 & 5 & $0 \%$ & 20.09 & $\underset{* *}{11.96 \pm 0.73}$ & & & & & & $\mathrm{ng} / \mathrm{mg}$ & 12 & 1 \\
\hline
\end{tabular}


Table 4. Cont.

\begin{tabular}{|c|c|c|c|c|c|c|c|c|c|c|c|c|c|c|c|c|c|}
\hline Reference & $\begin{array}{l}\text { Study } \\
\text { Group }\end{array}$ & Sample & Country & $\begin{array}{l}\text { Sample } \\
\text { Size }\end{array}$ & $\begin{array}{c}\text { Mean } \\
\text { Age }\end{array}$ & Female & Male & $\begin{array}{l}\text { Smoking } \\
\text { Status }\end{array}$ & $\begin{array}{c}\text { Mean } \\
\text { BMI }\end{array}$ & AM & GM & IQR & Range Median & CI & $\begin{array}{c}\text { Units } \\
\text { (8-OHdG/ } \\
\text { Creatinine) }\end{array}$ & $\begin{array}{c}\text { Computed } \\
\text { GM } \\
\text { (ng/mg } \\
\text { Creatinine) }\end{array}$ & GSD \\
\hline [60] & Male group & $\begin{array}{l}\text { spot } \\
\text { urine }\end{array}$ & Japan & 195 & 41.7 & 0 & 195 & $49.7 \%$ & 23.6 & $9.35 \pm 3.66^{*}$ & & & & & $\mathrm{ng} / \mathrm{mg}$ & 9 & 1 \\
\hline [60] & $\begin{array}{l}\text { Female } \\
\text { group }\end{array}$ & $\begin{array}{l}\text { spot } \\
\text { urine }\end{array}$ & Japan & 194 & 41.7 & 194 & 0 & $29.9 \%$ & 22.1 & $10.97 \pm 5^{*}$ & & & & & $\mathrm{ng} / \mathrm{mg}$ & 10 & 2 \\
\hline [61] & $\begin{array}{l}\text { Non MS } \\
\text { group }\end{array}$ & $\begin{array}{l}\text { spot } \\
\text { urine }\end{array}$ & Japan & 638 & 40.8 & 385 & 253 & $27.3 \%$ & 22.3 & $9.28 \pm 4.15 *$ & & & & & $\mathrm{ng} / \mathrm{mg}$ & 8 & 2 \\
\hline [62] & Male control & $\begin{array}{l}\text { spot } \\
\text { urine }\end{array}$ & Pakistan & 34 & 39.7 & 0 & 34 & $0 \%$ & 19.85 & $24.5 \pm 6.6^{*}$ & & & $11.08-33.855 .72$ & & $\mathrm{ng} / \mathrm{mg}$ & 26 & 1 \\
\hline [62] & $\begin{array}{l}\text { Female } \\
\text { control }\end{array}$ & $\begin{array}{l}\text { spot } \\
\text { urine }\end{array}$ & Pakistan & 32 & 39.52 & 32 & 0 & $0 \%$ & 20.83 & $24.5 \pm 6.33 *$ & & & $11.1-33.8524 .47$ & & $\mathrm{ng} / \mathrm{mg}$ & 24 & 1 \\
\hline [63] & $\begin{array}{l}\text { Control } \\
\text { group }\end{array}$ & $\begin{array}{l}\text { spot } \\
\text { urine }\end{array}$ & Pakistan & 34 & 39.7 & 0 & 34 & $0 \%$ & 20.9 & $24 \pm 4^{*}$ & & & $9-30$ & & $\mathrm{ng} / \mathrm{mg}$ & 25 & 1 \\
\hline [64] & $\begin{array}{l}\text { Control } \\
\text { group }\end{array}$ & $\begin{array}{l}\text { spot } \\
\text { urine }\end{array}$ & Pakistan & 34 & 37 & 0 & 34 & $0 \%$ & 20.8 & $25.8 \pm 7^{*}$ & & & $9.1-33.9 \quad 27.9$ & & $\mathrm{ng} / \mathrm{mg}$ & 28 & 1 \\
\hline [65] & $\begin{array}{c}\text { Pregnant } \\
\text { women }\end{array}$ & $\begin{array}{l}\text { spot } \\
\text { urine }\end{array}$ & Korea & 261 & 29.6 & 261 & 0 & $0 \%$ & 21 & $20.8 \pm 14.2^{*}$ & & & & & $\mu \mathrm{g} / \mathrm{g}$ & 17 & 2 \\
\hline [66] & $\begin{array}{c}\text { Control } \\
\text { group } \\
\text { baseline }\end{array}$ & $\begin{array}{l}\text { spot } \\
\text { urine }\end{array}$ & UK & 32 & 31.7 & 15 & 17 & $0 \%$ & 22.4 & $21.6 \pm 12.6^{*}$ & & & & & $\mathrm{ng} / \mathrm{mg}$ & 19 & 2 \\
\hline [66] & $\begin{array}{l}\text { Test group } \\
\text { baseline }\end{array}$ & $\begin{array}{l}\text { spot } \\
\text { urine }\end{array}$ & UK & 32 & 31.7 & 15 & 17 & $0 \%$ & 22.4 & $24 \pm 13.3 *$ & & & & & $\mathrm{ng} / \mathrm{mg}$ & 21 & 2 \\
\hline [67] & $\begin{array}{l}\text { Control } \\
\text { group }\end{array}$ & $\begin{array}{l}\text { spot } \\
\text { urine }\end{array}$ & Turkey & 20 & 40.7 & 10 & 10 & NA & 22.52 & $7.84 \pm 7.04$ * & & & & & $\mathrm{ng} / \mathrm{mg}$ & 6 & 2 \\
\hline [68] & $\begin{array}{l}\text { Control } \\
\text { group }\end{array}$ & $\begin{array}{l}\text { spot } \\
\text { urine }\end{array}$ & Japan & 108 & 23 & 0 & 108 & NA & 22.5 & $10.4 \pm 3.2 *$ & & & & & $\mathrm{ng} / \mathrm{mg}$ & 10 & 1 \\
\hline [69] & $\begin{array}{l}\text { Non exposed } \\
\text { group }\end{array}$ & $\begin{array}{l}\text { spot } \\
\text { urine }\end{array}$ & Iran & 43 & 35.58 & 0 & 43 & $21 \%$ & $19-24$ & $\begin{array}{l}54.16 \pm \\
26.98^{*}\end{array}$ & & & & & $\mathrm{ng} / \mathrm{mg}$ & 48 & 2 \\
\hline [70] & $\begin{array}{l}\text { Control } \\
\text { group }\end{array}$ & $\begin{array}{l}\text { spot } \\
\text { urine }\end{array}$ & Japan & 52 & 62.4 & 27 & 25 & $0 \%$ & 24 & $8.8 \pm 0.5^{* *}$ & & & & & $\mathrm{ng} / \mathrm{mg}$ & 8 & 1 \\
\hline [71] & Male group & $\begin{array}{l}\text { spot } \\
\text { urine }\end{array}$ & Japan & 276 & 42.1 & 0 & 276 & NA & 23.8 & $8.8 \pm 0.2^{* *}$ & & & & & $\mathrm{ng} / \mathrm{mg}$ & 8 & 1 \\
\hline [71] & $\begin{array}{c}\text { Female } \\
\text { group }\end{array}$ & $\begin{array}{l}\text { spot } \\
\text { urine }\end{array}$ & Japan & 445 & 42.7 & 445 & 0 & NA & 21.9 & $9.8 \pm 0.2^{* *}$ & & & & & $\mathrm{ng} / \mathrm{mg}$ & 9 & 2 \\
\hline
\end{tabular}


Table 4. Cont

\begin{tabular}{|c|c|c|c|c|c|c|c|c|c|c|c|c|c|c|c|c|c|c|}
\hline Reference & $\begin{array}{l}\text { Study } \\
\text { Group }\end{array}$ & Sample & Country & $\begin{array}{l}\text { Sample } \\
\text { Size }\end{array}$ & $\begin{array}{l}\text { Mean } \\
\text { Age }\end{array}$ & Female & Male & $\begin{array}{l}\text { Smoking } \\
\text { Status }\end{array}$ & $\begin{array}{c}\text { Mean } \\
\text { BMI }\end{array}$ & $\mathrm{AM}$ & GM & IQR & Range I & Median & CI & $\begin{array}{l}\text { Units } \\
\text { (8-OHdG/ } \\
\text { Creatinine) }\end{array}$ & $\begin{array}{c}\text { Computed } \\
\text { GM } \\
\text { (ng/mg } \\
\text { Creatinine) }\end{array}$ & GSD \\
\hline [72] & $\begin{array}{l}\text { Male healthy } \\
\text { population }\end{array}$ & $\begin{array}{l}\text { spot } \\
\text { urine }\end{array}$ & Japan & 142 & 43.6 & 0 & 142 & $31 \%$ & 22.4 & $11.5 \pm 5.2 *$ & & & & & & $\mathrm{ng} / \mathrm{mg}$ & 10 & 2 \\
\hline [72] & $\begin{array}{c}\text { Female } \\
\text { healthy } \\
\text { population }\end{array}$ & $\begin{array}{l}\text { spot } \\
\text { urine }\end{array}$ & Japan & 136 & 43.4 & 136 & 0 & $52.2 \%$ & 23.8 & $9.4 \pm 3.4$ * & & & & & & $\mathrm{ng} / \mathrm{mg}$ & 9 & 1 \\
\hline [73] & $\begin{array}{l}\text { Control } \\
\text { group }\end{array}$ & $\begin{array}{l}\text { spot } \\
\text { urine }\end{array}$ & USA & 43 & 32.6 & 43 & 0 & $0 \%$ & 23.2 & $6.31 \pm 2.49^{*}$ & & & & & & $\mathrm{ng} / \mathrm{mg}$ & 6 & 1 \\
\hline [74] & Male group & $\begin{array}{l}\text { spot } \\
\text { urine }\end{array}$ & Japan & 323 & 42 & 0 & 323 & $42.7 \%$ & 23.7 & $8.85 \pm 3.29$ & & & & & & $\mathrm{ng} / \mathrm{mg}$ & 8 & 1 \\
\hline [74] & $\begin{array}{l}\text { Female } \\
\text { group }\end{array}$ & $\begin{array}{l}\text { spot } \\
\text { urine }\end{array}$ & Japan & 443 & 42.7 & 443 & 0 & $13.5 \%$ & 21.9 & $9.89 \pm 4.54 *$ & & & & & & $\mathrm{ng} / \mathrm{mg}$ & 9 & 2 \\
\hline [75] & $\begin{array}{l}\text { Green tea } \\
\text { catechin-no } \\
\text { exercise } \\
\text { group } \\
\text { baseline } \\
\text { value }\end{array}$ & $\begin{array}{l}\text { spot } \\
\text { urine }\end{array}$ & Japan & 8 & 22.4 & 0 & 8 & $0 \%$ & $>18<25$ & $15.9 \pm 3.6^{*}$ & & & & & & $\mathrm{ng} / \mathrm{mg}$ & 16 & 1 \\
\hline [75] & $\begin{array}{l}\text { Green tea } \\
\text { catechin- } \\
\text { exercise } \\
\text { group } \\
\text { baseline } \\
\text { value }\end{array}$ & $\begin{array}{l}\text { spot } \\
\text { urine }\end{array}$ & Japan & 8 & 21.1 & 0 & 8 & $0 \%$ & $>18<25$ & $22.9 \pm 7.9^{*}$ & & & & & & $\mathrm{ng} / \mathrm{mg}$ & 22 & 1 \\
\hline [75] & $\begin{array}{l}\text { Placebo } \\
\text { group }\end{array}$ & $\begin{array}{l}\text { spot } \\
\text { urine }\end{array}$ & Japan & 8 & 21.1 & 0 & 8 & $0 \%$ & $>18<25$ & $18 \pm 6.2^{*}$ & & & & & & $\mathrm{ng} / \mathrm{mg}$ & 17 & 1 \\
\hline [76] & Men group & $\begin{array}{l}\text { spot } \\
\text { urine }\end{array}$ & Japan & 272 & 43.5 & 0 & 272 & $60.7 \%$ & 23.7 & $8.86 \pm 3.36^{*}$ & & & $2.13-21.87$ & & & $\mu g / g$ & 8 & 1 \\
\hline [76] & $\begin{array}{l}\text { Women } \\
\text { group }\end{array}$ & $\begin{array}{l}\text { spot } \\
\text { urine }\end{array}$ & Japan & 295 & 40.3 & 295 & 0 & $15.6 \%$ & 21.7 & $9.25 \pm 4.03 *$ & & & $0.05-25.56$ & & & $\mu \mathrm{g} / \mathrm{g}$ & 8 & 2 \\
\hline [77] & $\begin{array}{l}\text { Baseline } \\
\text { value } 50 \mathrm{~km} \\
\text { group }\end{array}$ & $\begin{array}{l}\text { spot } \\
\text { urine }\end{array}$ & Italy & 6 & 41.83 & NA & NA & $0 \%$ & 21.08 & $4.38 \pm 1.16^{*}$ & & & & & & $\mathrm{ng} / \mathrm{mg}$ & 4 & 1 \\
\hline [78] & $\begin{array}{l}\text { Summer Non } \\
\text { heating } \\
\text { season }\end{array}$ & $\begin{array}{l}\text { spot } \\
\text { urine }\end{array}$ & China & 34 & 47.9 & 34 & 0 & $0 \%$ & 23.2 & $12.7 \pm 4.7^{*}$ & & & $\begin{array}{l}2.60, \\
25.8\end{array}$ & 13.6 & & $\mathrm{ng} / \mathrm{mg}$ & 9 & 2 \\
\hline
\end{tabular}


Table 4. Cont.

\begin{tabular}{|c|c|c|c|c|c|c|c|c|c|c|c|c|c|c|c|c|c|c|}
\hline Reference & $\begin{array}{l}\text { Study } \\
\text { Group }\end{array}$ & Sample & Country & $\begin{array}{l}\text { Sample } \\
\text { Size }\end{array}$ & $\begin{array}{c}\text { Mean } \\
\text { Age }\end{array}$ & Female & Male & $\begin{array}{l}\text { Smoking } \\
\text { Status }\end{array}$ & $\begin{array}{c}\text { Mean } \\
\text { BMI }\end{array}$ & $\mathrm{AM}$ & GM & IQR & Range & Median & CI & $\begin{array}{c}\text { Units } \\
\text { (8-OHdG/ } \\
\text { Creatinine) }\end{array}$ & $\begin{array}{c}\text { Computed } \\
\text { GM } \\
\text { (ng/mg } \\
\text { Creatinine) }\end{array}$ & GSD \\
\hline [79] & $\begin{array}{c}\text { Healthy } \\
\text { volunteers } \\
\text { Young group }\end{array}$ & $\begin{array}{l}\text { spot } \\
\text { urine }\end{array}$ & Turkey & 30 & 41.6 & 22 & 8 & $0 \%$ & 22.1 & $3.24 \pm 1.54^{*}$ & & & & & & $\mathrm{ng} / \mathrm{mg}$ & 3 & 2 \\
\hline [79] & $\begin{array}{c}\text { Healthy } \\
\text { volunteers } \\
\text { Elderly } \\
\text { group }\end{array}$ & $\begin{array}{l}\text { spot } \\
\text { urine }\end{array}$ & Turkey & 30 & 69.1 & 20 & 10 & $0 \%$ & 23.6 & $5.74 \pm 2.68^{*}$ & & & & & & $\mathrm{ng} / \mathrm{mg}$ & 5 & 2 \\
\hline [80] & $\begin{array}{l}\text { Baseline } \\
\text { value }\end{array}$ & $\begin{array}{l}\text { spot } \\
\text { urine }\end{array}$ & China & 25 & 20.9 & 12 & 13 & $0 \%$ & 20.67 & $\begin{array}{c}3765.63 \pm \\
958.14^{*}\end{array}$ & & & & & & $\mathrm{ng} / \mathrm{mmol}$ & 32 & 1 \\
\hline [15] & $\begin{array}{l}\text { Women } \\
\text { group }\end{array}$ & $\begin{array}{l}\text { spot } \\
\text { urine }\end{array}$ & Italy & 33 & 30 & 33 & 0 & $29 \%$ & 20.7 & & & $3.68-7.20$ & & 5.21 & & $\mathrm{ng} / \mathrm{mg}$ & 4 & 2 \\
\hline [81] & $\begin{array}{c}\text { Non exposed } \\
\text { group }\end{array}$ & $\begin{array}{l}\text { spot } \\
\text { urine }\end{array}$ & China & 143 & 27.89 & 100 & 43 & $8 \%$ & 21.03 & $\underset{*}{17.36}+13.5$ & & & & & & $\mathrm{ng} / \mathrm{mg}$ & 14 & 2 \\
\hline
\end{tabular}

Table 5. References for urinary 8-OHdG concentrations measured and computed GM (ng/mg creatinine) with immunological techniques in healthy (mean BMI $>25$ and no known disease), adult (18+ years) participants.

\begin{tabular}{|c|c|c|c|c|c|c|c|c|c|c|c|c|c|c|c|c|}
\hline Reference & Study Group & Sample & Country & $\begin{array}{c}\text { Sample } \\
\text { Size }\end{array}$ & $\begin{array}{c}\text { Mean } \\
\text { Age }\end{array}$ & Female & Male & $\begin{array}{l}\text { Smoking } \\
\text { Status }\end{array}$ & $\begin{array}{c}\text { Mean } \\
\text { BMI }\end{array}$ & $\mathrm{AM}$ & IQR & Range & Median & $\begin{array}{c}\text { Units } \\
\text { (8-OHdG/ } \\
\text { Creatinine) }\end{array}$ & $\begin{array}{c}\text { Computed GM } \\
\text { (ng/mg } \\
\text { Creatinine) }\end{array}$ & GSD \\
\hline [82] & $\begin{array}{c}\text { Cocorit } \\
\text { communities }\end{array}$ & spot urine & Mexico & 10 & 45.9 & 5 & 5 & $30 \%$ & 27 & $8.2 \pm 4.3^{*}$ & & & & $\mu \mathrm{g} / \mathrm{g}$ & 7 & 2 \\
\hline [82] & $\begin{array}{l}\text { Pueblo Yaqui } \\
\text { communities }\end{array}$ & spot urine & Mexico & 15 & 35.3 & 9 & 6 & $7 \%$ & 26.7 & $5.7 \pm 2.9 *$ & & & & $\mu \mathrm{g} / \mathrm{g}$ & 5 & 2 \\
\hline [82] & Campo 47 & spot urine & Mexico & 15 & 39.5 & 10 & 5 & $40 \%$ & 29.8 & $5.7 \pm 3.3^{*}$ & & & & $\mu \mathrm{g} / \mathrm{g}$ & 5 & 2 \\
\hline [83] & Control group & spot urine & UK & 61 & 28.4 & 61 & 0 & $9 \%$ & 26 & $\begin{array}{l}39.83 \pm \\
2.92^{* *}\end{array}$ & & & & $\mathrm{ng} / \mathrm{mg}$ & 35 & 2 \\
\hline [55] & $\begin{array}{l}\text { Healthy older } \\
\text { group }\end{array}$ & $24 \mathrm{~h}$ urine & Canada & 12 & 71.8 & 0 & 12 & $0 \%$ & 28.8 & $\begin{array}{l}7714 \pm \\
1402 *\end{array}$ & & & & $\mathrm{ng} / \mathrm{g}$ & 8 & 1 \\
\hline [84] & $\begin{array}{c}\text { Water group } \\
\text { baseline value }\end{array}$ & spot urine & USA & 42 & $18-79$ & 32 & 10 & $100 \%$ & 25.9 & $\begin{array}{c}8.7 \pm 1.3 \\
* *\end{array}$ & & & & $\mathrm{ng} / \mathrm{mg}$ & 5 & 3 \\
\hline
\end{tabular}


Table 5. Cont

\begin{tabular}{|c|c|c|c|c|c|c|c|c|c|c|c|c|c|c|}
\hline Reference & Study Group & Sample & Country & $\begin{array}{l}\text { Sample } \\
\text { Size }\end{array}$ & $\begin{array}{c}\text { Mean } \\
\text { Age }\end{array}$ & Female & Male & $\begin{array}{l}\text { Smoking } \\
\text { Status }\end{array}$ & $\begin{array}{c}\text { Mean } \\
\text { BMI }\end{array}$ & $\mathrm{AM}$ & Range Median & $\begin{array}{l}\text { Units } \\
\text { (8-OHdG/ } \\
\text { Creatinine) }\end{array}$ & $\begin{array}{c}\text { Computed GM } \\
\text { (ng/mg } \\
\text { Creatinine) }\end{array}$ & GSD \\
\hline [84] & $\begin{array}{c}\text { Green tea group } \\
\text { baseline value }\end{array}$ & spot urine & USA & 35 & $18-79$ & 27 & 8 & $100 \%$ & 26.5 & $\underset{* *}{10.8 \pm 1.3}$ & & $\mathrm{ng} / \mathrm{mg}$ & 9 & 2 \\
\hline [84] & $\begin{array}{c}\text { Black tea } \\
\text { baseline value }\end{array}$ & spot urine & USA & 43 & $18-79$ & 31 & 12 & $100 \%$ & 26.7 & $\underset{* *}{9.5 \pm 2.1}$ & & $\mathrm{ng} / \mathrm{mg}$ & 6 & 2 \\
\hline [85] & $\begin{array}{c}\text { Water group } \\
\text { baseline value }\end{array}$ & spot urine & USA & 45 & 49.8 & 32 & 13 & $100 \%$ & 26.9 & $9.5 \pm 1.3$ & & $\mathrm{ng} / \mathrm{mg}$ & 6 & 3 \\
\hline [85] & $\begin{array}{c}\text { Black tea } \\
\text { baseline value }\end{array}$ & spot urine & USA & 46 & 52.1 & 34 & 12 & $100 \%$ & 27.2 & $\underset{* *}{10.8 \pm 2.5}$ & & $\mathrm{ng} / \mathrm{mg}$ & 7 & 2 \\
\hline [85] & $\begin{array}{c}\text { Green tea group } \\
\text { baseline value }\end{array}$ & spot urine & USA & 42 & 51.6 & 32 & 10 & $100 \%$ & 27.2 & $\underset{* *}{8.7 \pm 1.8}$ & & $\mathrm{ng} / \mathrm{mg}$ & 5 & 3 \\
\hline [86] & $\begin{array}{l}\text { Placebo group } \\
\text { baseline value }\end{array}$ & $24 \mathrm{~h}$ urine & USA & 47 & 58.1 & 23 & 24 & $0 \%$ & 28.9 & $\begin{array}{l}17.6 \pm \\
10.4^{*}\end{array}$ & & $\mathrm{ng} / \mathrm{mg}$ & 15 & 2 \\
\hline [86] & $\begin{array}{l}\text { Vit } C \text { group } \\
\text { baseline value }\end{array}$ & $24 \mathrm{~h}$ urine & USA & 46 & 61.2 & 26 & 20 & $0 \%$ & 28.7 & $\begin{array}{c}19.3 \pm 9.3 \\
*\end{array}$ & & $\mathrm{ng} / \mathrm{mg}$ & 17 & 2 \\
\hline [86] & $\begin{array}{l}\text { Vit E group } \\
\text { baseline value }\end{array}$ & $24 \mathrm{~h}$ urine & USA & 45 & 55.5 & 29 & 16 & $0 \%$ & 28.6 & $\begin{array}{c}16.5 \pm 8.4 \\
*\end{array}$ & & $\mathrm{ng} / \mathrm{mg}$ & 15 & 2 \\
\hline [86] & $\begin{array}{c}\text { Vit C + Vit E } \\
\text { baseline value }\end{array}$ & $24 \mathrm{~h}$ urine & USA & 46 & 57.7 & 24 & 22 & $0 \%$ & 28.9 & $\begin{array}{c}17.7 \pm 9.5 \\
*\end{array}$ & & $\mathrm{ng} / \mathrm{mg}$ & 16 & 2 \\
\hline [87] & Control group & $24 \mathrm{~h}$ urine & Finland & 100 & 65 & 46 & 54 & $18 \%$ & 27.7 & $\begin{array}{l}24.3 \pm \\
15.2 *\end{array}$ & & $\mathrm{ng} / \mathrm{mg}$ & 21 & 2 \\
\hline [88] & Control group & spot urine & Taiwan & 27 & 49 & 0 & 27 & $55.6 \%$ & 25.8 & $5 \pm 4.92 *$ & & $\mu \mathrm{g} / \mathrm{g}$ & 4 & 2 \\
\hline [89] & All population & spot urine & Japan & 90 & 52 & 60 & 30 & $0 \%$ & 25.2 & & $5.8-23.20 .90-48.0 \quad 9.3$ & $\mathrm{ng} / \mathrm{mg}$ & 9 & 3 \\
\hline [90] & Baseline value & spot urine & Canada & 28 & 68.5 & NA & NA & $0 \%$ & 27.1 & $\begin{array}{c}10783 \pm \\
5856^{*}\end{array}$ & & $\mathrm{ng} / \mathrm{g}$ & 9 & 2 \\
\hline [91] & $\begin{array}{l}\text { control group } \\
\text { baseline }\end{array}$ & spot urine & Spain & 23 & 30.42 & 23 & 0 & $0 \%$ & 25.32 & $\begin{array}{l}9.29 \pm \\
0.69 * *\end{array}$ & & $\mathrm{ng} / \mathrm{mg}$ & 9 & 1 \\
\hline [91] & $\begin{array}{l}\text { DHA group } \\
\text { baseline }\end{array}$ & spot urine & Spain & 23 & 29.97 & 23 & 0 & $0 \%$ & 25.62 & $\begin{array}{l}9.81 \pm \\
0.79 * *\end{array}$ & & $\mathrm{ng} / \mathrm{mg}$ & 9 & 1 \\
\hline [92] & $\begin{array}{l}\text { Placebo group } \\
\text { men }\end{array}$ & $24 \mathrm{~h}$ urine & Canada & 8 & 74.8 & 0 & 8 & $0 \%$ & 25.9 & $\begin{array}{l}8329 \pm \\
3032 *\end{array}$ & & $\mathrm{ng} / \mathrm{g}$ & 8 & 1 \\
\hline
\end{tabular}


Table 5. Cont.

\begin{tabular}{|c|c|c|c|c|c|c|c|c|c|c|c|c|c|c|c|c|}
\hline Reference & Study Group & Sample & Country & $\begin{array}{l}\text { Sample } \\
\text { Size }\end{array}$ & $\begin{array}{c}\text { Mean } \\
\text { Age }\end{array}$ & Female & Male & $\begin{array}{l}\text { Smoking } \\
\text { Status }\end{array}$ & $\begin{array}{c}\text { Mean } \\
\text { BMI }\end{array}$ & AM & IQR & Range & Median & $\begin{array}{l}\text { Units } \\
\text { (8-OHdG/ } \\
\text { Creatinine) }\end{array}$ & $\begin{array}{c}\text { Computed GM } \\
\text { (ng/mg } \\
\text { Creatinine) }\end{array}$ & GSD \\
\hline [92] & $\begin{array}{l}\text { Placebo group } \\
\text { women }\end{array}$ & $24 \mathrm{~h}$ urine & Canada & 10 & 68.3 & 10 & 0 & $0 \%$ & 25.2 & $\begin{array}{c}11622 \pm \\
4379 * \\
\end{array}$ & & & & $\mathrm{ng} / \mathrm{g}$ & 7 & 1 \\
\hline [92] & $\begin{array}{l}\text { Intervention } \\
\text { group men } \\
\text { baseline }\end{array}$ & $24 \mathrm{~h}$ urine & Canada & 11 & 71.8 & 0 & 11 & $0 \%$ & 27.8 & $\begin{array}{l}7245 \pm \\
2703^{*}\end{array}$ & & & & $\mathrm{ng} / \mathrm{g}$ & 11 & 1 \\
\hline [92] & $\begin{array}{l}\text { Intervention } \\
\text { group women } \\
\text { baseline }\end{array}$ & $24 \mathrm{~h}$ urine & Canada & 10 & 69.5 & 10 & 0 & $0 \%$ & 25.5 & $\begin{array}{l}7942 \pm \\
3071^{*}\end{array}$ & & & & $\mathrm{ng} / \mathrm{g}$ & 7 & 1 \\
\hline [15] & $\begin{array}{l}\text { Men group early } \\
\text { morning }\end{array}$ & spot urine & Italy & 22 & 34 & 0 & 22 & $38.1 \%$ & 25.3 & & $2.76-5.25$ & & 3.76 & $\mathrm{ng} / \mathrm{mg}$ & 5 & 2 \\
\hline
\end{tabular}

* SD; ** SEM. 


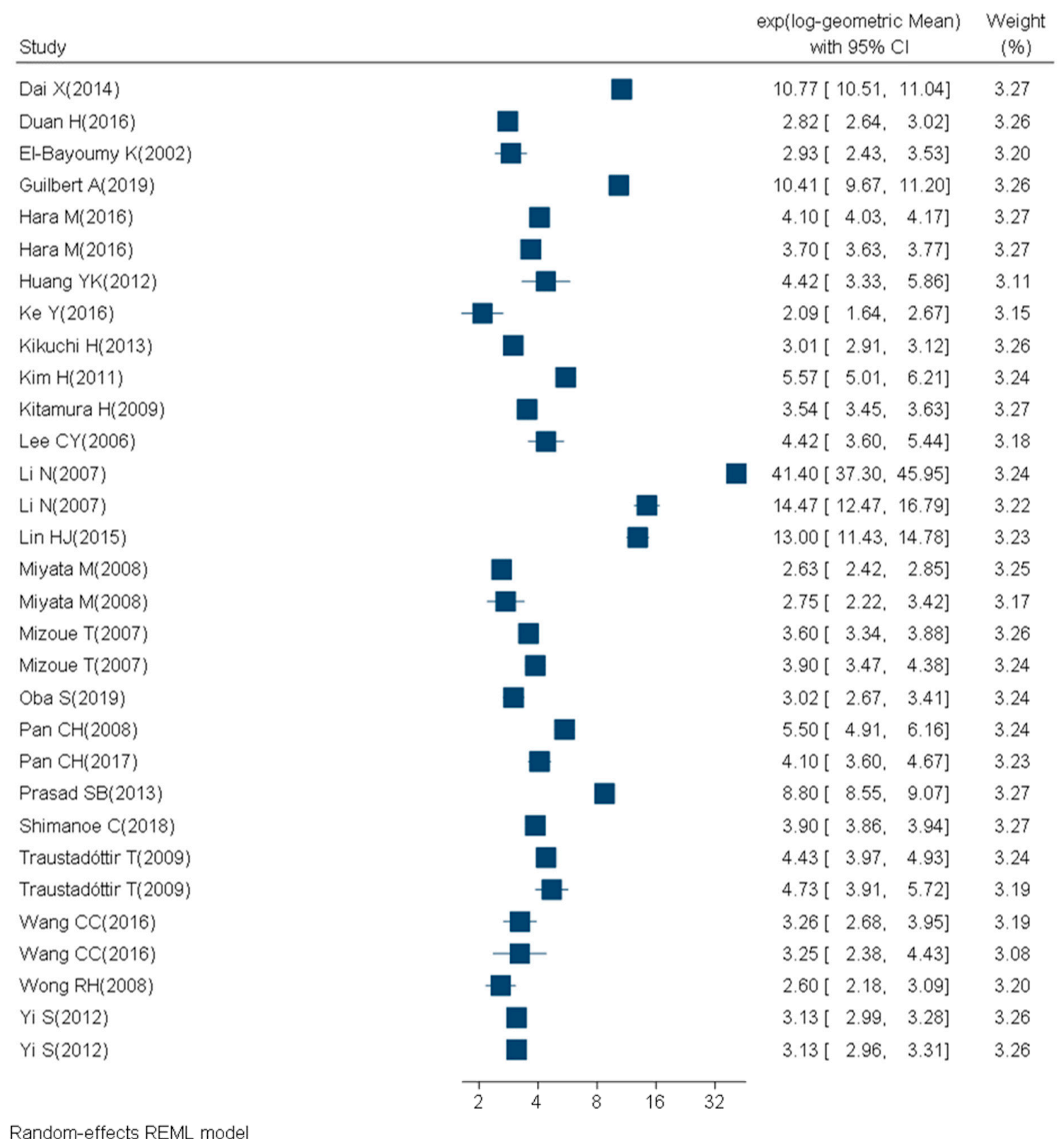

Figure 3. Forest plot of urinary $8-\mathrm{OHdG}$ concentrations (ng/mg creatinine) measured with chemical techniques in healthy (mean BMI $\leq 25$ and no known disease), adult (18+ years) participants.

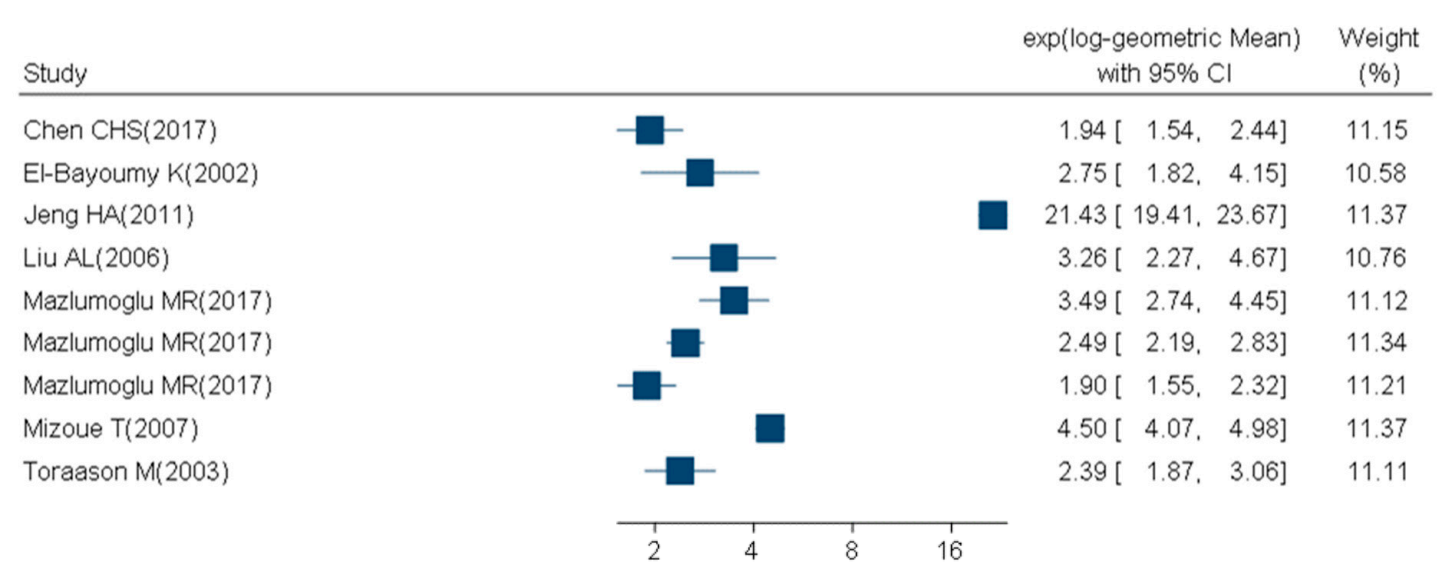

Random-effects REML model

Figure 4. Forest plot of urinary 8-OHdG levels (ng/mg creatinine) measured with chemical techniques in healthy (mean BMI $>25$ and no known disease), adult (18+ years) participants 
For subgroups analyzed with immunological techniques, 47 studies had participants with a mean BMI between 18 and 25 (24 study subgroups of nonsmokers, no study subgroups of smokers and 6 study subgroups with unknown smoking status) (Figure 5, Table 4). Twenty-six studies had participants with a mean BMI > 25 (13 study subgroups of nonsmokers and 6 study subgroups of smokers) (Figure 6, Table 5). The mean BMI was unknown for 11 study subgroups. Supplementary material provides detailed information on the criteria used for the quality assessment (S1) and on the quality level of each included study subgroup (S2). Overall, two study subgroups (1.8\%) were classified as low quality, $66(58.4 \%)$ as moderate quality, and 45 study subgroups (39.8\%) were of high quality.

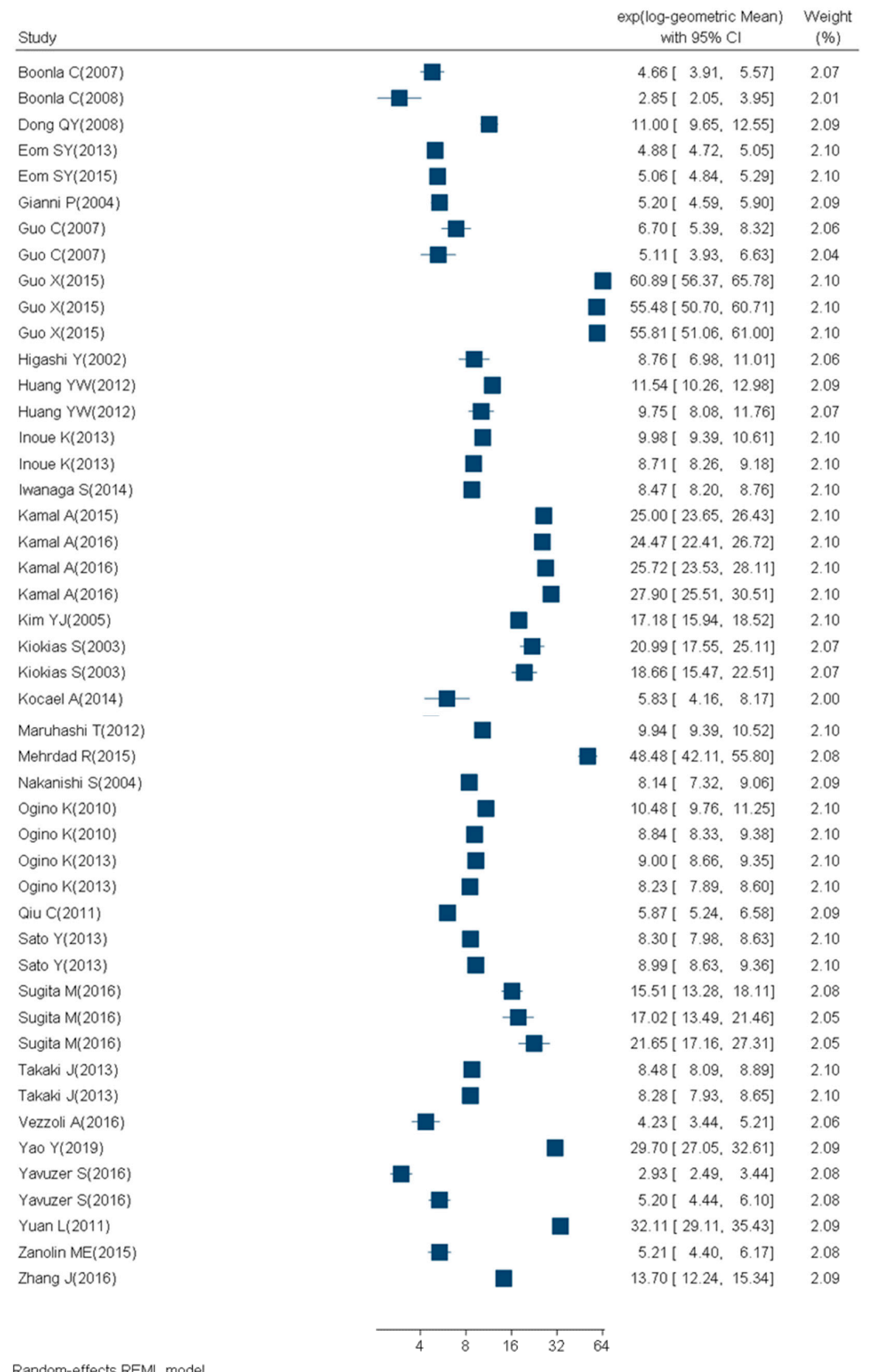

Figure 5. Forest plot of urinary 8-OHdG concentrations (ng/mg creatinine) measured with immunological techniques in healthy (mean BMI $\leq 25$ and no known disease), adult (18+ years) participants. 


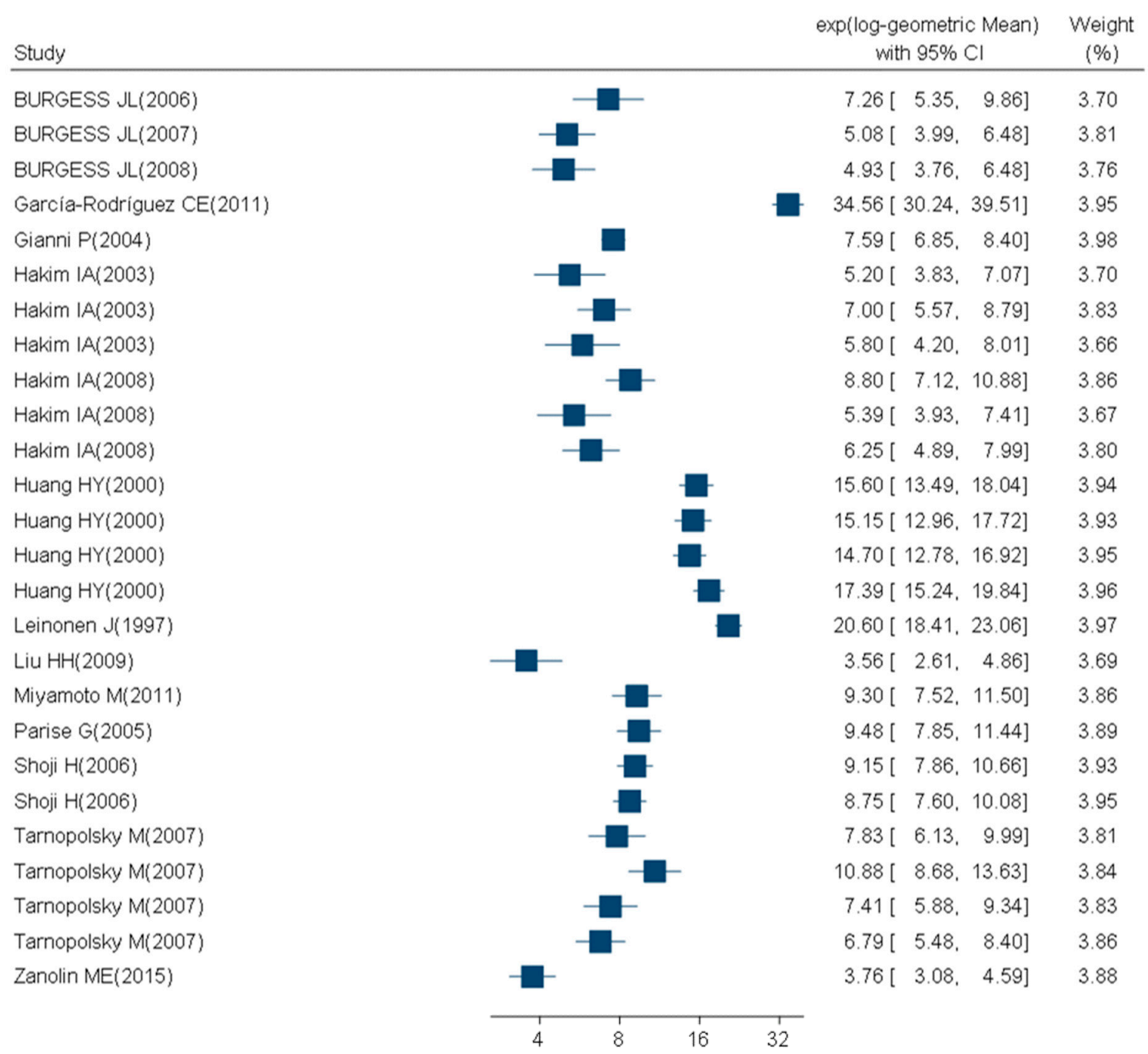

Random-effects REML model

Figure 6. Forest plot of urinary $8-\mathrm{OHdG}$ concentrations (ng/mg creatinine) measured with immunological techniques in healthy (mean BMI > 25 and no known disease), adult (18+ years) participants.

\subsection{Meta-Analysis Results}

As between-study heterogeneity was much larger than the between-subject heterogeneity, we decided to use a mixed model with study ID as a random effect. The IQR of subgroup-specific GM in subgroups with a mean BMI $\leq 25$ with 8 -OHdG measured using chemical methods was 3 to $5.5 \mathrm{ng} / \mathrm{mg}$ creatinine (Table 1). IQR of subgroup-specific GM in subgroups with a mean BMI $>25$ measured using immunological methods was 5.9 to $19.8 \mathrm{ng} / \mathrm{mg}$ creatinine (Table 1 ).

We compared urinary 8-OHdG concentrations by smoking status within the study subgroups analyzed with chemical techniques and found that for study subgroups with mean BMI $\leq 25$, smokers were $2.84([2.56,3.16], p<0.0001)$ times greater compared to nonsmoker study subgroups.

For study subgroups with mean BMI $>25$, smokers were $1.61([1.17,2.23], p=0.004)$ times greater compared to the nonsmoker study.

No consistent effects of BMI and gender were observed in our mixed model either for chemical or immunological methods. Gender and BMI seem to not influence urinary 8-OHdG concentrations. 


\section{Discussion}

\subsection{Interpretation of Findings}

We found that urinary $8-\mathrm{OHdG}$ concentrations in smokers were greater than in nonsmokers when analysis was conducted with chemical techniques. However, in the population with mean BMI between 18 and 25, this finding was mainly due to one study [32] and needs to be confirmed. The absence of BMI effect on 8-OHdG in urine is in line with data from Lee et al. 2010 [93].

The IQR range for 8-OHdG in urine given in this meta-analysis is in line with two other studies trying to define reference values for the Italian population (female: $3.25-6.85 \mathrm{ng} / \mathrm{mg}$ creatinine; male: 2.9-5.5 ng/mg creatinine) [94]. The absence of gender effect observed for 8-OHdG in this study is in line with data from the Italian population [94] but in contradiction with two others [93,95].

The analysis of the data was difficult due to the diversity in study design, analytical methods (chemical or immunoassay techniques), statistical analysis, and data presentation in studies included.

\subsection{Quantification of $8-O H d G$}

The heterogeneity in techniques used to quantify urinary 8-OHdG makes it more difficult to compare data between laboratories.

Chemical techniques are superior to immunological techniques due to their sensitivity and specificity [14,96]. Chemical techniques require expensive instruments and trained users, but we recommend using chemical quantification methods as standard methods for future studies of biomonitoring.

\subsection{Lack of Homogeneity in Data Collection and Reporting}

Most studies used spot urine samples for 8-OHdG rather than 12- or 24-h collection. However, 8-OHdG levels showed fluctuation during the day under oxidative states [97], but good correlations have been observed between levels of 8-OHdG in spot morning urine and levels of 8-OHdG in the 24-h urinary collection [14]. Therefore, we included studies reporting spot morning urine, 12- or 24-h urinary samples. The first morning urine void is particularly valuable because it provides a time average for biomarker concentrations that may occur during the hours of sleep (approximately $8 \mathrm{~h}$ ) and is also relatively free of dietary, physical, and environmental exposures [15]. A significant increase in time in the urinary $8-\mathrm{OHdG}$ during the first part of the day was recently reported among smokers [15]. To make it easier to compare results between studies, we recommend collecting spot morning urine.

\subsection{Limitations}

We confirm that smokers have a significantly greater concentration of urinary 8-OHdG, as has been previously reported in the literature. The concentration differences need to be quantified, but with only a few studies in smokers available, this cannot be done at the present time.

We emphasize here that the values we report are for a healthy population. We were not able to analyze parameters previously reported to influence 8-OHdG concentrations such as occupation, pregnancy, special diet, vitamin, and physical activity due to the limited number of studies with such data.

\subsection{Recommendations}

The fluctuation in urine flow rate could in fact affect the assessment of urinary 8-OHdG. The urinary 8-OHdG concentrations need to be normalized by urinary creatinine concentrations for healthy adults. Different studies indicated a correlation between excretion of creatinine and 8-OHdG [94,95]. In addition, normalization with creatinine for spot urine can be considered as a surrogate for the 24-h excretion of 8-OHdG [94,98]. 
To reach consensual background of urinary 8-OHdG values, harmonization of the unit (ng/mg creatinine) is needed. Harmonization of the statistical reporting of the results is also recommended (geometric means (GM) and geometric standard deviations (GSD)). We suggest reporting the median and the 1st and 3rd quartile as GSDs are not easy to interpret.

\section{Materials and Methods}

We established a standardized protocol for systematic review and meta-analysis for a set of biomarkers of oxidative stress. This protocol was registered in the International Prospective Register of Systematic Reviews (registration number CRD 42020146623) [99] and described in detail by Hemmendinger et al. [100]. The protocol was then adapted for each biomarker depending on the biological matrix focused, here the urinary 8-OHdG. The methods and results of this study are reported following recommendations from Preferred Reporting Items for Systematic Reviews and Meta-Analyses (PRISMA) recommendations [101,102].

\subsection{Literature Search}

The search strategy was done with a medical librarian. The MeSH (Medical Subject Headings) terms from the PubMed database and free text words were combined. The complete search string was: ("Smoking/urine"[Mesh] OR “Urine"[Mesh] OR Urine*[tiab] OR Urinary[tiab] OR Urinal*[tiab]) AND ("8-oxo-7-hydrodeoxyguanosine"[Supplementary Concept] OR 8-OHdg[tw] OR 8ohdg[tw] OR 8-oh-dg[tw] OR 8-ohg[tw] OR 8-OH-2dG[tw] OR 8-hydroxydeoxyguanosine[tw] OR 8-hydroxyguanine[tw] OR 8-hydroxy-g[tw] OR 8-hydroxy-dg[tw] OR 8-hydroxy-guanine[tw] OR 8-hydroxy-2-deoxyguanosine[tw]) NOT (“"Child”[Mesh] OR “Infant”[Mesh] OR “Adolescent”[MeSH]) NOT “adult"[MeSH]) NOT (animals[mh] NOT humans[mh]).

\subsection{Study Selection}

The search was performed on 7 May 2019. Rayyan [103], a systematic review web application, was used for title and abstract screening. We selected the studies in a stepwise process as depicted in Figure 6. To be included in the analysis, a study had to be in English and to provide urinary 8-OHdG concentrations in healthy adults (ages 18-no upper age limit) populations. We excluded non-human studies, in vitro studies, reviews, letters, expert opinions, and editorials. We read the eligible articles in depth, and only studies with original data from healthy (no known disease) adult populations were included in the statistical analysis. All techniques used for the quantification of 8-OHdG were included and classified accordingly. We excluded studies with coefficient variation $<10 \%$ or $>200 \%$. We also excluded data suspected to have unit or reported value mistakes (more than three orders of magnitude higher than the median levels).

\subsection{Data Extraction}

We extracted the following information: first author name, publication year, study type, country, analytic method, sample time, sample size, gender, mean age, mean BMI, smoking status, season, occupation, pregnancy, diet, vitamin, exercise, outcome (8-OHdG concentration), references, and article DOI. We extracted all subgroup-specific data when data on several subgroups were available in a given paper. Then, we excluded all subgroups selected based on disease status (e.g., cardiovascular disease) and all subgroups selected based on an exposure status (e.g., bus drivers). If data on the same subgroup were reported for different times (e.g., different seasons), only the data at the time of participant inclusion were included. In a third round, we excluded duplicate data (e.g., control population reported in more than one study) and retained the most complete and the most recent study. 


\subsection{Statistical Analysis}

First, we analyzed the values of urinary 8 -OHdG measured in original studies in view of establishing the background ranges using meta-analysis. Measured values were generally log-normally distributed. We therefore computed geometric means (GM) and geometric standard deviations (GSD) as the basis for the meta-analysis or equivalently $m u L=\ln (G M)$ and $s d L=\ln (G S D)$. Further details on the data treatment and analyses are available elsewhere [104].

We could not compute standard errors on the geometric (or arithmetic) scale when neither standard deviation (SD), GSD, IQR, nor confidence interval (CI) were reported. As a consequence, we excluded these studies from the meta-analysis. We converted all the concentration values to the same units (ng/mg creatinine) before computing GM and GSD. We used $113.12 \mathrm{~g} / \mathrm{mol}$ for the molecular weight for creatinine and $283.24 \mathrm{~g} / \mathrm{mol}$ for 8-OHdG. We regrouped the data according to analytical techniques used; immunological techniques and chemical techniques. The data were analyzed separately.

We followed standard practice in meta-analysis [105] and represent the data as forest plots including the I-squared. This is an estimate of the between-study heterogeneity in percentage. If the between-study heterogeneity is much larger than the between-subject heterogeneity, then $\mathrm{I}^{2}$ is large. In this case, any attempt of obtaining a background value for individual participants will not be valid. In our case, a mixed model with study ID as a random effect is a more relevant analysis model. This yields results on the study subgroup level rather than at the individual level. Data management and statistical analyses were performed in STATA version 16 software.

\section{Conclusions}

We report pooled GM values for urinary 8-OHdG in healthy adults, separately for chemical and immunological methods. We observed a significant positive association between smoking status and urinary $8-\mathrm{OHdG}$ concentrations when measured by chemical analysis. No gender effect was shown. Urinary 8-OHdG can potentially be used to quantify excess oxidative stress due to external exposures when background values have been established in different populations. We recommend adjusting urine samples with creatinine, quantifying $8-\mathrm{OHdG}$ with chemical methods, and reporting results as median and quartiles. Comparing values across studies will then be feasible.

Supplementary Materials: Supplementary Materials can be found at http://www.mdpi.com/1422-0067/21/11/ 3743/s1.

Author Contributions: I.G.C. and N.B.H. conceived the project, developed the necessary tools, and managed funding acquisition; M.H. and M.G. wrote the study protocol and implemented the literature search; M.G. and N.B.H. performed the screening for study selection, the systematic review, and data extraction; J.-J.S. performed data conversion and validation; P.W. realized statistical analysis; M.G. wrote the manuscript, which was further amended by all authors. All authors have read and agreed to the published version of the manuscript.

Funding: This study was conducted within the framework of EU Life Project "NanoExplore" (Grant $N^{\circ}$ LIFE17 ENV/GR/000285) and Franco-Swiss project "ROBoCoP" (Swiss National Science Foundation Grant $\mathrm{N}^{\circ}$ IZCOZ0_177067).

Conflicts of Interest: The authors declare no conflict of interest.

\section{Abbreviations}

$\begin{array}{ll}\text { 8-OHdG } & \text { 8-hydroxy-2-deoxyguanosine } \\ \text { ROS } & \text { Reactive oxygen species } \\ \text { GM } & \text { Geometric mean } \\ \text { GSD } & \text { Geometric standard deviation } \\ \text { BMI } & \text { Body mass index } \\ \text { SD } & \text { Standard deviation } \\ \text { SEM } & \text { Standard error of the mean } \\ \text { CV } & \text { Coefficient of variation } \\ \text { IQR } & \text { Interquartile range }\end{array}$




\section{References}

1. Lushchak, V.I. Free radicals, reactive oxygen species, oxidative stress and its classification. Chem. Biol. Interact. 2014, 224, 164-175. [CrossRef] [PubMed]

2. Shigenaga, M.K.; Gimeno, C.J.; Ames, B.N. Urinary 8-hydroxy-2'-deoxyguanosine as a biological marker of in vivo oxidative DNA damage. Proc. Natl. Acad. Sci. USA 1989, 86, 9697-9701. [CrossRef] [PubMed]

3. Kasai, H. Analysis of a form of oxidative DNA damage, 8-hydroxy-2'-deoxyguanosine, as a marker of cellular oxidative stress during carcinogenesis. Mutat. Res. 1997, 387, 147-163. [CrossRef]

4. Beckman, K.B.; Ames, B.N. Oxidative decay of DNA. J. Biol. Chem. 1997, 272, 19633-19636. [CrossRef]

5. Kasai, H.; Hayami, H.; Yamaizumi, Z.; Saito, H.; Nishimura, S. Detection and identification of mutagens and carcinogens as their adducts with guanosine derivatives. Nucleic Acids Res. 1984, 12, 2127-2136. [CrossRef]

6. Valavanidis, A.; Vlachogianni, T.; Fiotakis, C. 8-hydroxy-2' -deoxyguanosine (8-ohdg): A critical biomarker of oxidative stress and carcinogenesis. J. Environ. Sci. Health Part C Environ. Carcinog. Ecotoxicol. Rev. 2009, 27, 120-139. [CrossRef]

7. Di Minno, A.; Turnu, L.; Porro, B.; Squellerio, I.; Cavalca, V.; Tremoli, E.; Di Minno, M.N. 8-hydroxy-2-deoxyguanosine levels and cardiovascular disease: A systematic review and meta-analysis of the literature. Antioxid. Redox Signal. 2016, 24, 548-555. [CrossRef]

8. Neofytou, E.; Tzortzaki, E.G.; Chatziantoniou, A.; Siafakas, N.M. DNA damage due to oxidative stress in chronic obstructive pulmonary disease (copd). Int. J. Mol. Sci. 2012, 13, 16853-16864. [CrossRef]

9. Abusoglu, S.; Celik, H.T.; Tutkun, E.; Yilmaz, H.; Serdar, M.A.; Bal, C.D.; Yildirimkaya, M.; Avcikucuk, M. 8-hydroxydeoxyguanosine as a useful marker for determining the severity of trichloroethylene exposure. Arch. Environ. Occup. Health 2014, 69, 180-186. [CrossRef]

10. Sakano, N.; Wang, D.H.; Takahashi, N.; Wang, B.; Sauriasari, R.; Kanbara, S.; Sato, Y.; Takigawa, T.; Takaki, J.; Ogino, K. Oxidative stress biomarkers and lifestyles in japanese healthy people. J. Clin. Biochem. Nutr. 2009, 44, 185-195. [CrossRef]

11. Martinez-Moral, M.P.; Kannan, K. How stable is oxidative stress level? An observational study of intra- and inter-individual variability in urinary oxidative stress biomarkers of DNA, proteins, and lipids in healthy individuals. Environ. Int. 2019, 123, 382-389. [CrossRef] [PubMed]

12. Hopf, N.B.; Bourgkard, E.; Demange, V.; Hulo, S.; Sauvain, J.J.; Levilly, R.; Jeandel, F.; Robert, A.; Guichard, Y.; Pralong, J.A.; et al. Early effect markers and exposure determinants of metalworking fluids among metal industry workers: Protocol for a field study. JMIR Res. Protoc. 2019, 8, e13744. [CrossRef] [PubMed]

13. Bergamaschi, E.; Poland, C.; Guseva Canu, I.; Prina-Mello, A. The role of biological monitoring in nano-safety. Nano Today 2015, 10, 274-277. [CrossRef]

14. Barregard, L.; Moller, P.; Henriksen, T.; Mistry, V.; Koppen, G.; Rossner, P., Jr.; Sram, R.J.; Weimann, A.; Poulsen, H.E.; Nataf, R.; et al. Human and methodological sources of variability in the measurement of urinary 8-oxo-7,8-dihydro-2'-deoxyguanosine. Antioxid. Redox Signal. 2013, 18, 2377-2391. [CrossRef]

15. Zanolin, M.E.; Girardi, P.; Degan, P.; Rava, M.; Olivieri, M.; Di Gennaro, G.; Nicolis, M.; De Marco, R. Measurement of a urinary marker (8-hydroxydeoxy-guanosine, 8-ohdg) of DNA oxidative stress in epidemiological surveys: A pilot study. Int. J. Biol. Markers 2015, 30, e341-e345. [CrossRef] [PubMed]

16. Cooke, M.S.; Olinski, R.; Loft, S. Measurement and meaning of oxidatively modified DNA lesions in urine. Cancer Epidemiol. Biomark. Prev. 2008, 17, 3-14. [CrossRef] [PubMed]

17. Rossner, P., Jr.; Mistry, V.; Singh, R.; Sram, R.J.; Cooke, M.S. Urinary 8-oxo-7,8-dihydro-2'-deoxyguanosine values determined by a modified elisa improves agreement with hplc-ms/ms. Biochem. Biophys. Res. Commun. 2013, 440, 725-730. [CrossRef]

18. Chamitava, L.; Garcia-Larsen, V.; Cazzoletti, L.; Degan, P.; Pasini, A.; Bellisario, V.; Corsico, A.G.; Nicolis, M.; Olivieri, M.; Pirina, P.; et al. Determination of adjusted reference intervals of urinary biomarkers of oxidative stress in healthy adults using gamlss models. PLoS ONE 2018, 13, e0206176. [CrossRef]

19. Wang, D.H.; Yamada, A.; Miyanaga, M. Changes in urinary hydrogen peroxide and 8-hydroxy-2'-deoxyguanosine levels after a forest walk: A pilot study. Int. J. Environ. Res. Public Health 2018, 15, 1871. [CrossRef]

20. Tada, S.; Shiota, A.; Hayashi, H.; Nakamura, T. Reference urinary biopyrrin level and physiological variation in healthy young adults: Relation of stress by learning. Heliyon 2020, 6, e03138. [CrossRef] 
21. Dai, X.; Deng, S.; Wang, T.; Qiu, G.; Li, J.; Yang, B.; Feng, W.; He, X.; Deng, Q.; Ye, J.; et al. Associations between 25 lung cancer risk-related snps and polycyclic aromatic hydrocarbon-induced genetic damage in coke oven workers. Cancer Epidemiol. Biomark. Prev. 2014, 23, 986-996. [CrossRef]

22. Duan, H.; Jia, X.; Zhai, Q.; Ma, L.; Wang, S.; Huang, C.; Wang, H.; Niu, Y.; Li, X.; Dai, Y.; et al. Long-term exposure to diesel engine exhaust induces primary DNA damage: A population-based study. Occup. Environ. Med. 2016, 73, 83-90. [CrossRef] [PubMed]

23. El-Bayoumy, K.; Richie, J.P., Jr.; Boyiri, T.; Komninou, D.; Prokopczyk, B.; Trushin, N.; Kleinman, W.; Cox, J.; Pittman, B.; Colosimo, S. Influence of selenium-enriched yeast supplementation on biomarkers of oxidative damage and hormone status in healthy adult males: A clinical pilot study. Cancer Epidemiol. Biomark. Prev. 2002, 11, 1459-1465.

24. Guilbert, A.; De Cremer, K.; Heene, B.; Demoury, C.; Aerts, R.; Declerck, P.; Brasseur, O.; Van Nieuwenhuyse, A. Personal exposure to traffic-related air pollutants and relationships with respiratory symptoms and oxidative stress: A pilot cross-sectional study among urban green space workers. Sci. Total Environ. 2019, 649, 620-628. [CrossRef] [PubMed]

25. Hara, M.; Nishida, Y.; Shimanoe, C.; Otsuka, Y.; Nanri, H.; Yasukata, J.; Miyoshi, N.; Yamada, Y.; Horita, M.; Kawai, K.; et al. Intensity-specific effect of physical activity on urinary levels of 8-hydroxydeoxyguanosine in middle-aged japanese. Cancer Sci. 2016, 107, 1653-1659. [CrossRef] [PubMed]

26. Huang, Y.K.; Lin, C.W.; Chang, C.C.; Chen, P.F.; Wang, C.J.; Hsueh, Y.M.; Chiang, H.C. Heat acclimation decreased oxidative DNA damage resulting from exposure to high heat in an occupational setting. Eur. J. Appl. Physiol. 2012, 112, 4119-4126. [CrossRef]

27. Ke, Y.; Huang, L.; Xia, J.; Xu, X.; Liu, H.; Li, Y.R. Comparative study of oxidative stress biomarkers in urine of cooks exposed to three types of cooking-related particles. Toxicol. Lett. 2016, 255, 36-42. [CrossRef]

28. Kikuchi, H.; Nanri, A.; Hori, A.; Sato, M.; Kawai, K.; Kasai, H.; Mizoue, T. Lower serum levels of total cholesterol are associated with higher urinary levels of 8-hydroxydeoxyguanosine. Nutr. Metab. 2013, 10, 59. [CrossRef]

29. Kim, H.; Ku, S.Y.; Kang, J.W.; Kim, H.; Kim, Y.D.; Kim, S.H.; Choi, Y.M.; Kim, J.G.; Moon, S.Y. The 8-hydroxydeoxyguanosine concentrations according to hormone therapy and s326c polymorphism of ogg1 gene in postmenopausal women. Mol. Genet. Metab. 2011, 104, 644-647. [CrossRef]

30. Kitamura, H.; Terunuma, N.; Kurosaki, S.; Hata, K.; Ide, R.; Kuga, H.; Kakiuchi, N.; Masuda, M.; Totsuzaki, T.; Osato, A.; et al. Cross-sectional study on respiratory effect of toner-exposed work in manufacturing plants, japan: Pulmonary function, blood cells, and biochemical markers. Hum. Exp. Toxicol. 2009, 28, 331-338. [CrossRef]

31. Lee, C.Y.; Isaac, H.B.; Wang, H.; Huang, S.H.; Long, L.H.; Jenner, A.M.; Kelly, R.P.; Halliwell, B. Cautions in the use of biomarkers of oxidative damage; the vascular and antioxidant effects of dark soy sauce in humans. Biochem. Biophys. Res. Commun. 2006, 344, 906-911. [CrossRef] [PubMed]

32. Li, N.; Jia, X.; Chen, C.Y.O.; Blumberg, J.B.; Song, Y.; Zhang, W.; Zhang, X.; Ma, G.; Chen, J. Almond consumption reduces oxidative DNA damage and lipid peroxidation in male smokers. J. Nutr. 2007, 137, 2717-2722. [CrossRef] [PubMed]

33. Lin, H.J.; Chen, S.T.; Wu, H.Y.; Hsu, H.C.; Chen, M.F.; Lee, Y.T.; Wu, K.Y.; Chien, K.L. Urinary biomarkers of oxidative and nitrosative stress and the risk for incident stroke: A nested case-control study from a community-based cohort. Int. J. Cardiol. 2015, 183, 214-220. [CrossRef] [PubMed]

34. Miyata, M.; Kasai, H.; Kawai, K.; Yamada, N.; Tokudome, M.; Ichikawa, H.; Goto, C.; Tokudome, Y.; Kuriki, K.; Hoshino, H.; et al. Changes of urinary 8-hydroxydeoxyguanosine levels during a two-day ultramarathon race period in japanese non-professional runners. Int. J. Sports Med. 2008, 29, 27-33. [CrossRef]

35. Mizoue, T.; Tokunaga, S.; Kasai, H.; Kawai, K.; Sato, M.; Kubo, T. Body mass index and oxidative DNA damage: A longitudinal study. Cancer Sci. 2007, 98, 1254-1258. [CrossRef]

36. Oba, S.; Inaba, Y.; Shibuya, T.; Oshima, J.; Seyama, K.; Kobayashi, T.; Kunugita, N.; Ino, T. Changes in oxidative stress levels during two weeks of smoking cessation treatment and their association with nutritional characteristics in japanese smokers. Exp. Ther. Med. 2019, 17, 2757-2764. [CrossRef]

37. Pan, C.H.; Jeng, H.A.; Lai, C.H. Biomarkers of oxidative stress in electroplating workers exposed to hexavalent chromium. J. Expo. Sci. Environ. Epidemiol. 2018, 28, 76-83. [CrossRef] 
38. Pan, C.H.; Chan, C.C.; Wu, K.Y. Effects on chinese restaurant workers of exposure to cooking oil fumes: A cautionary note on urinary 8-hydroxy-2'-deoxyguanosine. Cancer Epidemiol. Biomark. Prev. 2008, 17, 3351-3357. [CrossRef]

39. Prasad, S.B.; Vidyullatha, P.; Vani, G.T.; Devi, R.P.; Rani, U.P.; Reddy, P.P.; Prasad, H.M. Association of gene polymorphism in detoxification enzymes and urinary 8-ohdg levels in traffic policemen exposed to vehicular exhaust. Inhal. Toxicol. 2013, 25, 1-8.

40. Shimanoe, C.; Hara, M.; Nishida, Y.; Nanri, H.; Horita, M.; Yamada, Y.; Li, Y.S.; Kasai, H.; Kawai, K.; Higaki, Y.; et al. Perceived stress, depressive symptoms, and oxidative DNA damage. Psychosom. Med. 2018, 80, $28-33$. [CrossRef]

41. Traustadottir, T.; Davies, S.S.; Stock, A.A.; Su, Y.; Heward, C.B.; Roberts, L.J., 2nd; Harman, S.M. Tart cherry juice decreases oxidative stress in healthy older men and women. J. Nutr. 2009, 139, 1896-1900. [CrossRef] [PubMed]

42. Wang, C.C.; Chen, W.L.; Lin, C.M.; Lai, C.H.; Loh, C.H.; Chen, H.I.; Liou, S.H. The relationship between plasma and urinary 8-hydroxy-2-deoxyguanosine biomarkers measured by liquid chromatography tandem mass spectrometry. Environ. Sci. Pollut. Res. Int. 2016, 23, 17496-17502. [CrossRef] [PubMed]

43. Wong, R.H.; Hu, C.W.; Yeh, C.Y.; Chao, M.R.; Chen, C.C.; Huang, J.H.; Chang, S.H.; Lee, S.I.; Lee, H.S. Sulfotransferase $1 \mathrm{a} 1$ and glutathione s-transferase $\mathrm{p} 1$ genetic polymorphisms modulate the levels of urinary 8-hydroxy-2'-deoxyguanosine in betel quid chewers. Arch. Toxicol. 2008, 82, 313-321. [CrossRef] [PubMed]

44. Yi, S.; Nanri, A.; Matsushita, Y.; Kasai, H.; Kawai, K.; Mizoue, T. Depressive symptoms and oxidative DNA damage in japanese municipal employees. Psychiatry Res. 2012, 200, 318-322. [CrossRef]

45. Chen, C.S.; Yuan, T.H.; Shie, R.H.; Wu, K.Y.; Chan, C.C. Linking sources to early effects by profiling urine metabolome of residents living near oil refineries and coal-fired power plants. Environ. Int. 2017, 102, 87-96. [CrossRef]

46. Jeng, H.A.; Pan, C.H.; Diawara, N.; Chang-Chien, G.P.; Lin, W.Y.; Huang, C.T.; Ho, C.K.; Wu, M.T. Polycyclic aromatic hydrocarbon-induced oxidative stress and lipid peroxidation in relation to immunological alteration. Occup. Environ. Med. 2011, 68, 653-658. [CrossRef]

47. Liu, A.L.; Lu, W.Q.; Wang, Z.Z.; Chen, W.H.; Lu, W.H.; Yuan, J.; Nan, P.H.; Sun, J.Y.; Zou, Y.L.; Zhou, L.H.; et al. Elevated levels of urinary 8-hydroxy-2 -deoxyguanosine, lymphocytic micronuclei, and serum glutathione s-transferase in workers exposed to coke oven emissions. Environ. Health Perspect. 2006, 114, 673-677. [CrossRef]

48. Mazlumoglu, M.R.; Ozkan, O.; Alp, H.H.; Ozyildirim, E.; Bingol, F.; Yoruk, O.; Kuduban, O. Measuring oxidative DNA damage with 8-hydroxy-2'-deoxyguanosine levels in patients with laryngeal cancer. Ann. Otol. Rhinol. Laryngol. 2017, 126, 103-109. [CrossRef]

49. Toraason, M.; Butler, M.A.; Ruder, A.; Forrester, C.; Taylor, L.; Ashley, D.L.; Mathias, P.; Marlow, K.L.; Cheever, K.L.; Krieg, E.; et al. Effect of perchloroethylene, smoking, and race on oxidative DNA damage in female dry cleaners. Mutat. Res. 2003, 539, 9-18. [CrossRef]

50. Boonla, C.; Hunapathed, C.; Bovornpadungkitti, S.; Poonpirome, K.; Tungsanga, K.; Sampatanukul, P.; Tosukhowong, P. Messenger rna expression of monocyte chemoattractant protein-1 and interleukin- 6 in stone-containing kidneys. BJU Int. 2008, 101, 1170-1177. [CrossRef]

51. Boonla, C.; Wunsuwan, R.; Tungsanga, K.; Tosukhowong, P. Urinary 8-hydroxydeoxyguanosine is elevated in patients with nephrolithiasis. Urol. Res. 2007, 35, 185-191. [CrossRef] [PubMed]

52. Dong, Q.Y.; Cui, Y.; Chen, L.; Song, J.; Sun, L. Urinary 8-hydroxydeoxyguanosine levels in diabetic retinopathy patients. Eur. J. Ophthalmol. 2008, 18, 94-98. [CrossRef]

53. Eom, S.Y.; Yim, D.H.; Lee, C.H.; Choe, K.H.; An, J.Y.; Lee, K.Y.; Kim, Y.D.; Kim, H. Interactions between paraoxonase 1 genetic polymorphisms and smoking and their effects on oxidative stress and lung cancer risk in a korean population. PLoS ONE 2015, 10, e0119100. [CrossRef] [PubMed]

54. Eom, S.Y.; Yim, D.H.; Moon, S.I.; Youn, J.W.; Kwon, H.J.; Oh, H.C.; Yang, J.J.; Park, S.K.; Yoo, K.Y.; Kim, H.S.; et al. Polycyclic aromatic hydrocarbon-induced oxidative stress, antioxidant capacity, and the risk of lung cancer: A pilot nested case-control study. Anticancer Res. 2013, 33, 3089-3097. [PubMed]

55. Gianni, P.; Jan, K.J.; Douglas, M.J.; Stuart, P.M.; Tarnopolsky, M.A. Oxidative stress and the mitochondrial theory of aging in human skeletal muscle. Exp. Gerontol. 2004, 39, 1391-1400. [CrossRef] [PubMed]

56. Guo, C.; Wei, J.; Yang, J.; Xu, J.; Pang, W.; Jiang, Y. Pomegranate juice is potentially better than apple juice in improving antioxidant function in elderly subjects. Nutr. Res. 2008, 28, 72-77. [CrossRef] 
57. Guo, X.; Cui, H.; Zhang, H.; Guan, X.; Zhang, Z.; Jia, C.; Wu, J.; Yang, H.; Qiu, W.; Zhang, C.; et al. Protective effect of folic acid on oxidative DNA damage: A randomized, double-blind, and placebo controlled clinical trial. Medicine 2015, 94, e1872. [CrossRef]

58. Higashi, Y.; Sasaki, S.; Nakagawa, K.; Matsuura, H.; Oshima, T.; Chayama, K. Endothelial function and oxidative stress in renovascular hypertension. N. Engl. J. Med. 2002, 346, 1954-1962. [CrossRef]

59. Huang, Y.W.; Jian, L.; Zhang, M.B.; Zhou, Q.; Yan, X.F.; Hua, X.D.; Zhou, Y.; He, J.L. An investigation of oxidative DNA damage in pharmacy technicians exposed to antineoplastic drugs in two chinese hospitals using the urinary 8-ohdg assay. Biomed. Environ. Sci. 2012, 25, 109-116.

60. Inoue, K.; Sakano, N.; Ogino, K.; Sato, Y.; Wang, D.H.; Kubo, M.; Takahashi, H.; Kanbara, S.; Miyatake, N. Relationship between ceruloplasmin and oxidative biomarkers including ferritin among healthy japanese. J. Clin. Biochem. Nutr. 2013, 52, 160-166. [CrossRef]

61. Iwanaga, S.; Sakano, N.; Taketa, K.; Takahashi, N.; Wang, D.H.; Takahashi, H.; Kubo, M.; Miyatake, N.; Ogino, K. Comparison of serum ferritin and oxidative stress biomarkers between japanese workers with and without metabolic syndrome. Obes. Res. Clin. Pract. 2014, 8, e201-e298. [CrossRef] [PubMed]

62. Kamal, A.; Cincinelli, A.; Martellini, T.; Malik, R.N. Biomarkers of pah exposure and hematologic effects in subjects exposed to combustion emission during residential (and professional) cooking practices in pakistan. Environ. Sci. Pollut. Res. Int. 2016, 23, 1284-1299. [CrossRef]

63. Kamal, A.; Cincinelli, A.; Martellini, T.; Malik, R.N. Linking mobile source-pahs and biological effects in traffic police officers and drivers in rawalpindi (pakistan). Ecotoxicol. Environ. Saf. 2016, 127, 135-143. [CrossRef] [PubMed]

64. Kamal, A.; Cincinelli, A.; Martellini, T.; Palchetti, I.; Bettazzi, F.; Malik, R.N. Health and carcinogenic risk evaluation for cohorts exposed to pahs in petrochemical workplaces in rawalpindi city (pakistan). Int. J. Environ. Health Res. 2016, 26, 37-57. [CrossRef] [PubMed]

65. Kim, Y.J.; Hong, Y.C.; Lee, K.H.; Park, H.J.; Park, E.A.; Moon, H.S.; Ha, E.H. Oxidative stress in pregnant women and birth weight reduction. Reprod. Toxicol. 2005, 19, 487-492. [CrossRef] [PubMed]

66. Kiokias, S.; Gordon, M.H. Dietary supplementation with a natural carotenoid mixture decreases oxidative stress. Eur. J. Clin. Nutr. 2003, 57, 1135-1140. [CrossRef]

67. Kocael, A.; Erman, H.; Zengin, K.; Kocael, P.C.; Korkmaz, G.G.; Gelisgen, R.; Taskin, M.; Ersan, Y.; Uzun, H. The effects on oxidative DNA damage of laparoscopic gastric band applications in morbidly obese patients. Can. J. Surg. 2014, 57, 183-187. [CrossRef]

68. Maruhashi, T.; Soga, J.; Fujimura, N.; Idei, N.; Mikami, S.; Iwamoto, Y.; Kajikawa, M.; Matsumoto, T.; Kihara, Y.; Chayama, K.; et al. Hyperbilirubinemia, augmentation of endothelial function, and decrease in oxidative stress in gilbert syndrome. Circulation 2012, 126, 598-603. [CrossRef]

69. Mehrdad, R.; Aghdaei, S.; Pouryaghoub, G. Urinary 8-hydroxy-deoxyguanosine as a biomarker of oxidative DNA damage in employees of subway system. Acta Med. Iran. 2015, 53, 287-292.

70. Nakanishi, S.; Suzuki, G.; Kusunoki, Y.; Yamane, K.; Egusa, G.; Kohno, N. Increasing of oxidative stress from mitochondria in type 2 diabetic patients. Diabetes Metab. Res. Rev. 2004, 20, 399-404. [CrossRef]

71. Ogino, K.; Murakami, I.; Wang, D.H.; Tsukiyama, Y.; Takahashi, H.; Kubo, M.; Sakano, N.; Setiawan, H.; Bando, M.; Ohmoto, Y. Evaluation of serum arginase i as an oxidative stress biomarker in a healthy japanese population using a newly established elisa. Clin. Biochem. 2013, 46, 1717-1722. [CrossRef]

72. Ogino, K.; Takahashi, N.; Takigawa, T.; Obase, Y.; Wang, D.H. Association of serum arginase i with oxidative stress in a healthy population. Free Radic. Res. 2011, 45, 147-155. [CrossRef]

73. Qiu, C.; Hevner, K.; Abetew, D.; Enquobahrie, D.A.; Williams, M.A. Oxidative DNA damage in early pregnancy and risk of gestational diabetes mellitus: A pilot study. Clin. Biochem. 2011, 44, 804-808. [CrossRef] [PubMed]

74. Sato, Y.; Ogino, K.; Sakano, N.; Wang, D.H.; Yoshida, J.; Akazawa, Y.; Kanbara, S.; Inoue, K.; Kubo, M.; Takahashi, H. Evaluation of urinary hydrogen peroxide as an oxidative stress biomarker in a healthy japanese population. Free Radic. Res. 2013, 47, 181-191. [CrossRef]

75. Sugita, M.; Kapoor, M.P.; Nishimura, A.; Okubo, T. Influence of green tea catechins on oxidative stress metabolites at rest and during exercise in healthy humans. Nutrition 2016, 32, 321-331. [CrossRef] [PubMed]

76. Takaki, J. Associations of job stress indicators with oxidative biomarkers in japanese men and women. Int. J. Environ. Res. Public Health 2013, 10, 6662-6671. [CrossRef] [PubMed] 
77. Vezzoli, A.; Dellanoce, C.; Mrakic-Sposta, S.; Montorsi, M.; Moretti, S.; Tonini, A.; Pratali, L.; Accinni, R. Oxidative stress assessment in response to ultraendurance exercise: Thiols redox status and ros production according to duration of a competitive race. Oxidative Med. Cell. Longev. 2016, 2016, 6439037. [CrossRef]

78. Yao, Y.; Wang, D.; Ma, H.; Li, C.; Chang, X.; Low, P.; Hammond, S.K.; Turyk, M.E.; Wang, J.; Liu, S. The impact on t-regulatory cell related immune responses in rural women exposed to polycyclic aromatic hydrocarbons (pahs) in household air pollution in Gansu, China: A pilot investigation. Environ. Res. 2019, 173, 306-317. [CrossRef]

79. Yavuzer, S.; Yavuzer, H.; Cengiz, M.; Erman, H.; Demirdag, F.; Doventas, A.; Balci, H.; Erdincler, D.S.; Uzun, $\mathrm{H}$. The role of protein oxidation and DNA damage in elderly hypertension. Aging Clin. Exp. Res. 2016, 28, 625-632. [CrossRef]

80. Yuan, L.; Meng, L.; Ma, W.; Xiao, Z.; Zhu, X.; Feng, J.F.; Yu, H.; Xiao, R. Impact of apple and grape juice consumption on the antioxidant status in healthy subjects. Int. J. Food Sci. Nutr. 2011, 62, 844-850. [CrossRef]

81. Zhang, J.; Bao, J.; Wang, R.; Geng, Z.; Chen, Y.; Liu, X.; Xie, Y.; Jiang, L.; Deng, Y.; Liu, G.; et al. A multicenter study of biological effects assessment of pharmacy workers occupationally exposed to antineoplastic drugs in pharmacy intravenous admixture services. J. Hazard. Mater. 2016, 315, 86-92. [CrossRef]

82. Burgess, J.L.; Meza, M.M.; Josyula, A.B.; Poplin, G.S.; Kopplin, M.J.; McClellen, H.E.; Stürup, S.; Lantz, R.C. Environmental arsenic exposure and urinary 8-ohdg in arizona and sonora. Clin. Toxicol. 2007, 45, 490-498. [CrossRef] [PubMed]

83. García-Rodríguez, C.E.; Helmersson-Karlqvist, J.; Mesa, M.D.; Miles, E.A.; Noakes, P.S.; Vlachava, M.; Kremmyda, L.S.; Diaper, N.D.; Godfrey, K.M.; Calder, P.C.; et al. Does increased intake of salmon increase markers of oxidative stress in pregnant women? The salmon in pregnancy study. Antioxid. Redox Signal. 2011, 15, 2819-2823. [CrossRef] [PubMed]

84. Hakim, I.A.; Chow, H.H.; Harris, R.B. Green tea consumption is associated with decreased DNA damage among gstm1-positive smokers regardless of their hogg1 genotype. J. Nutr. 2008, 138,1567s-1571s. [CrossRef] [PubMed]

85. Hakim, I.A.; Harris, R.B.; Brown, S.; Chow, H.H.; Wiseman, S.; Agarwal, S.; Talbot, W. Effect of increased tea consumption on oxidative DNA damage among smokers: A randomized controlled study. J. Nutr. 2003, 133, 3303s-3309s. [CrossRef]

86. Huang, H.Y.; Helzlsouer, K.J.; Appel, L.J. The effects of vitamin c and vitamin e on oxidative DNA damage: Results from a randomized controlled trial. Cancer Epidemiol. Biomark. Prev. 2000, 9, 647-652.

87. Leinonen, J.; Lehtimäki, T.; Toyokuni, S.; Okada, K.; Tanaka, T.; Hiai, H.; Ochi, H.; Laippala, P.; Rantalaiho, V.; Wirta, O.; et al. New biomarker evidence of oxidative DNA damage in patients with non-insulin-dependent diabetes mellitus. FEBS Lett. 1997, 417, 150-152. [CrossRef]

88. Liu, H.H.; Lin, M.H.; Liu, P.C.; Chan, C.I.; Chen, H.L. Health risk assessment by measuring plasma malondialdehyde (mda), urinary 8-hydroxydeoxyguanosine (8-oh-dg) and DNA strand breakage following metal exposure in foundry workers. J. Hazard. Mater. 2009, 170, 699-704. [CrossRef]

89. Miyamoto, M.; Kotani, K.; Ishibashi, S.; Taniguchi, N. The relationship between urinary 8-hydroxydeoxyguanosine and metabolic risk factors in asymptomatic subjects. Med. Princ. Pract. 2011, 20, 187-190. [CrossRef]

90. Parise, G.; Brose, A.N.; Tarnopolsky, M.A. Resistance exercise training decreases oxidative damage to DNA and increases cytochrome oxidase activity in older adults. Exp. Gerontol. 2005, 40, 173-180. [CrossRef]

91. Shoji, H.; Franke, C.; Campoy, C.; Rivero, M.; Demmelmair, H.; Koletzko, B. Effect of docosahexaenoic acid and eicosapentaenoic acid supplementation on oxidative stress levels during pregnancy. Free Radic. Res. 2006, 40, 379-384. [CrossRef] [PubMed]

92. Tarnopolsky, M.; Zimmer, A.; Paikin, J.; Safdar, A.; Aboud, A.; Pearce, E.; Roy, B.; Doherty, T. Creatine monohydrate and conjugated linoleic acid improve strength and body composition following resistance exercise in older adults. PLoS ONE 2007, 2, e991. [CrossRef] [PubMed]

93. Lee, K.F.; Chung, W.Y.; Benzie, I.F. Urine 8-oxo-7,8-dihydro-2'-deoxyguanosine (8-oxodg), a specific marker of oxidative stress, using direct, isocratic lc-ms/ms: Method evaluation and application in study of biological variation in healthy adults. Clin. Chim. Acta Int. J. Clin. Chem. 2010, 411, 416-422. [CrossRef] [PubMed]

94. Andreoli, R.; Mutti, A.; Goldoni, M.; Manini, P.; Apostoli, P.; De Palma, G. Reference ranges of urinary biomarkers of oxidized guanine in (2'-deoxy)ribonucleotides and nucleic acids. Free Radic. Biol. Med. 2011, 50, 254-261. [CrossRef] [PubMed] 
95. Topic, A.; Francuski, D.; Markovic, B.; Stankovic, M.; Dobrivojevic, S.; Drca, S.; Radojkovic, D. Gender-related reference intervals of urinary 8-oxo-7,8-dihydro-2'-deoxyguanosine determined by liquid chromatography-tandem mass spectrometry in serbian population. Clin. Biochem. 2013, 46, 321-326. [CrossRef] [PubMed]

96. Evans, M.D.; Olinski, R.; Loft, S.; Cooke, M.S. Toward consensus in the analysis of urinary 8-oxo-7,8-dihydro-2'-deoxyguanosine as a noninvasive biomarker of oxidative stress. FASEB J. Off. Publ. Fed. Am. Soc. Exp. Biol. 2010, 24, 1249-1260.

97. Kanabrocki, E.L.; Murray, D.; Hermida, R.C.; Scott, G.S.; Bremner, W.F.; Ryan, M.D.; Ayala, D.E.; Third, J.L.; Shirazi, P.; Nemchausky, B.A.; et al. Circadian variation in oxidative stress markers in healthy and type ii diabetic men. Chronobiol. Int. 2002, 19, 423-439. [CrossRef]

98. Poulsen, H.E.; Loft, S.; Prieme, H.; Vistisen, K.; Lykkesfeldt, J.; Nyyssonen, K.; Salonen, J.T. Oxidative DNA damage in vivo: Relationship to age, plasma antioxidants, drug metabolism, glutathione-s-transferase activity and urinary creatinine excretion. Free Radic. Res. 1998, 29, 565-571. [CrossRef]

99. Hemmendinger, M.; Graille, M.; Wild, P.; Shoman, Y.; Bergamaschi, E.; Donato, F.; Hopf, N.; Guseva Canu, I. Baseline Values, between and within Subject Variability of Non-Invasive Biomarkers of Inflammation and Oxidative Stress: A Systematic Review and Meta-Analysis. PROSPERO 2020 CRD42020146623: 2020. Available online: https://www.crd.york.ac.uk/prospero/display_record.php?ID=CRD42020146623 (accessed on 9 March 2020).

100. Hemmendinger, M.; Wild, P.; Shoman, Y.; Graille, M.; Bergamaschi, E.; Hopf, N.; Guseva Canu, I. Reference ranges of oxidative stress biomarkers selected for non-invasive biological surveillance of nanotechnology workers: Study protocol and meta-analysis results for 8-ohdg in exhaled breath condensate. Toxicol. Lett. 2020, 327, 41-47. [CrossRef]

101. Moher, D.; Shamseer, L.; Clarke, M.; Ghersi, D.; Liberati, A.; Petticrew, M.; Shekelle, P.; Stewart, L.A. Preferred reporting items for systematic review and meta-analysis protocols (prisma-p) 2015 statement. Syst. Rev. 2015, 4, 1. [CrossRef]

102. Moher, D.; Liberati, A.; Tetzlaff, J.; Altman, D.G. Preferred reporting items for systematic reviews and meta-analyses: The prisma statement. J. Clin. Epidemiol. 2009, 62, 1006-1012. [CrossRef] [PubMed]

103. Ouzzani, M.; Hammady, H.; Fedorowicz, Z.; Elmagarmid, A. Rayyan-a web and mobile app for systematic reviews. Syst. Rev. 2016, 5, 210. [CrossRef] [PubMed]

104. Graille, M.; Wild, P.; Sauvain, J.J.; Hemmendinger, M.; Guseva-Canua, I.; Hopf, N.B. Urinary 8-isoprostane as a biomarker for oxidative stress: A systematic review and meta-analysis. Toxicol. Lett. 2020, in press. [CrossRef] [PubMed]

105. McKenzie, J.E.; Brennan, S.E.; Ryan, R.E.; Thomson, H.J.; Johnston, R.V. Summarizing study characteristics and preparing for synthesis. In Cochrane Handbook for Systematic Reviews of Interventions, 2nd ed.; John Wiley \& Sons: Chichester, UK, 2019; pp. 229-240. 